\title{
Bundling and Competition for Slots: On the Portfolio Effects of Bundling*
}

\author{
Doh-Shin Jeon $^{\dagger}$ and Domenico Menicucci ${ }^{\ddagger}$
}

July 27, 2009

\begin{abstract}
We consider competition among sellers when each of them sells a portfolio of distinct products to a buyer having limited slots. We study how bundling affects competition for slots. Under independent pricing, equilibrium often does not exist and hence the outcome is often inefficient. When bundling is allowed, each seller has an incentive to bundle his products and an efficient equilibrium always exists. Furthermore, in the case of digital goods, all equilibria are efficient if slotting contracts are prohibited. We also identify portfolio effects of bundling and analyze the consequences on horizontal mergers. Finally, we derive clear-cut policy implications.

Key words: Bundling, Portfolios, Slots (or Shelf Space), Pure Bundling, Slotting Contracts, Exclusive Dealing, Foreclosure
\end{abstract}

JEL Code: D4, K21, L13, L41, L82

*We thank the participants of seminars at Georgia Institute of Technology, IESE Business School, Korea University, Université de Cergy-Pontoise, University of Oxford, Université Paris X and of presentations at EARIE08, Net Institute Conference 08, PET08, SED 08, Workshop on Market Power in Vertically Related Markets (Toulouse) 09, CSIO-IDEI IO Workshop 09. We also thank the comments from Jung-Hyun Ahn, Eric Avenel, Jay Pil Choi, Jacques Crémer, Denis Gromb, Bruno Jullien, Byung-Cheol Kim, Volker Nocke, Patrick Rey, Régis Renault and in particular Michael Whinston. Jeon gratefully acknowledges the financial support from the Spanish government under SEJ2006-09993/ECON.

†Toulouse School of Economics, Universitat Pompeu Fabra and CEPR. dohshin.jeon@gmail.com

$\ddagger$ Università degli Studi di Firenze, Italy. domenico.menicucci@dmd.unifi.it 


\section{Introduction}

There are many situations in which sellers with different portfolios of products compete for limited slots (or shelf space) of a buyer who wants to build up her own portfolio of distinct products. In this situation, sellers may employ bundling as a strategy to win the competition for slots. Even though bundling has been a major antitrust issue and a subject of intensive research, to the best of our knowledge, the literature seems to have paid little attention to competition among portfolios of distinct products and, in particular, no paper seems to have studied how bundling affects portfolios' competition for slots. In this paper, we attempt to provide a new perspective on bundling by addressing this issue.

Examples of situations we described above are abundant both among digital products and among physical products. For instance, in the movie industry, each movie distributor has a portfolio of distinct movies and buyers (either movie theaters or TV stations) have limited slots. More precisely, the number of movies that can be projected in a season (or in a year) by a theater is constrained by time and the number of projection rooms. Likewise, the number of movies that a TV station can show during prime time of a season (or year) is limited. Actually, allocation of slots in movie theaters has been one of the main issues raised in the movie industry during the last presidential election in France. ${ }^{1}$ Furthermore, bundling in the movie industry (known as block booking ${ }^{2}$ ) was declared illegal in two Supreme Court decisions in U.S.: Paramount Pictures (1948), where blocks of films were rented for theatrical exhibition, and Loew's (1962), where blocks of films were rented for television exhibition. In addition, recently in MCA Television Ltd. v. Public Interest Corp. (11th Circuit, April 1999), the court of appeals reaffirmed the per se illegal status of block booking.

A different situation we have in mind is that of manufacturers' competition for retailers' shelf space. Manufacturers having a portfolio of products may practice bundling (often called full-line forcing) to win competition for slots, ${ }^{3}$ and there have been antitrust cases

\footnotetext{
${ }^{1}$ Cahiers du Cinema (April, 2007) proposes to limit the number copies per movie since certain movies by saturating screens restrict other movies' access to screens and asks each presidential candidate's opinion about the policy proposal.

${ }^{2}$ Block booking refers to "the practice of licensing, or offering for license, one feature or group of features on the condition that the exhibitor will also license another feature or group of features released by distributors during a given period" (Unites States v. Paramount Pictures, Inc., 334 U.S. 131 , 156 (1948)).

${ }^{3}$ For instance, Procter and Gamble uses 'golden-store' arrangement such that to be considerd a golden store, a retailer must agree to carry 40 or so P\&G items displayed together. See "P\&G has big plans for the shelves of tiny stores in emgering nations", Wall Street Journal, July 17, 2007.
} 
related to this practice. ${ }^{4}$ For instance, the French Competition Authority fined Société des Caves de Roquefort for using selectivity or exclusivity contracts with supermarket chains. ${ }^{5}$ Furthermore, slotting arrangements, the payment by manufacturers for retail shelf space, have become increasingly important and have been the subject of recent antitrust litigations ${ }^{6}$ and the focus of Federal Trade Commission studies. ${ }^{7}$

In our model, we assume away buyer's private information, which allows us to depart from the existing literature on bundling that usually considers a framework of seconddegree price discrimination and to identify what seems to us a first-order effect of bundling. Actually, in the case of movie industry, Kenney and Klein (1983) point out that second-order price discrimination explanation of bundling is inconsistent with the facts of Paramount and Loew's since the prices of the blocks varied a great deal across markets. Furthermore, in the Digital era, the prices are more and more tailored to buyers' characteristics as in the case of pricing of academic journals (Edlin and Rubinfeld 2004, Jeon and Menicucci 2006).

We consider a simultaneous pricing game among $n$ sellers (or firms) who sell their products to a buyer having $k(>0)$ number of slots. Each seller $i$ has a portfolio of $n_{i}$ distinct products. We assume that the prototype of each product is already made and call a product a digital good (a physical good) if the cost of producing a copy is zero (strictly positive). The buyer has a unit demand for each product. In our setting, a product needs to occupy a slot to generate a value. Products have heterogenous values and the values are independent. ${ }^{8}$ Social efficiency requires the slots to be allocated to the best $k$ products among all products. In this setup, we study how the outcome of competition depends on the nature of products (digital goods versus physical goods) and different bilateral contractual arrangements between each seller and the buyer.

Given a portfolio of products belonging to a firm, we define bundling as a menu contract

\footnotetext{
${ }^{4}$ Société des Caves de Roquefort, Conseil de la Concurrence, Decision 04-D-13, 8th April 2004. R.J. Reynolds Tobacco Co. v. Philip Morris, Inc., 199 F. Supp. 2d 363 (M.D.N.C. 2002). In the second case, Reynolds Tobacco accused Philip Morris for using "Retail Leaders" contract that provides discounts to retailers on its popular Marlboro brand in exchange for the most advantageous display and signage space in retail establishments.

${ }^{5}$ Société des Caves de Roquefort's market share in the Roquefort cheese market was $70 \%$ but, through the contract, could occupy eight among all nine brands that Carrefour, a supermarket chain, sold.

${ }^{6}$ See, for instances, American Booksellers Ass'n, Inc. v. Barnes \& Noble, Inc., 135 F. Supp. 2d 1031 (N.D. Cal. 2001); Intimate Bookshop, Inc. v. Barnes \& Noble, Inc., 88 F. Supp. 2d 133 (S.D.N.Y. 2000); FTC v. H.J. Heinz Co., 116 F. Supp. 2d 190 (D.C.C. 2000), rev'd, 246 F.3d 708 (D.C. Cir. 2001).

${ }^{7}$ See FTC Report (2001) and FTC Study (2003).

${ }^{8}$ In other words, the value that a product generates does not depend on the set of the other products that occupy the slots. This assumption is for simplicity and our results hold at least for simple substitutions among products (see the end of section 6).
} 
that specifies a price for every subset of the portfolio. A particular class of bundling contracts is what we call "independent pricing plus a fixed fee". A strategy in this class consists of a fixed fee for the right to buy products in the portfolio and one individual price for each product. There are three interesting special cases of this class. Individual pricing corresponds to the case with zero fixed fee; pure bundling corresponds to the case with zero individual prices; a "technology-renting" strategy is the case in which each individual price is equal to the cost of production.

Interestingly, the change from independent pricing to bundling opens a new contractual dimension, i.e. contracting on slots. Note that under independent pricing, the buyer will purchase only those products that would occupy a slot and therefore slotting contracts are redundant. In contrast, under bundling, for instance, if all firms offer pure bundles, the buyer may end up buying more products than the slots and hence we need to distinguish bundling with slotting contracts from bundling without slotting contracts. A slotting contract is defined such that if a bundle is sold with a slotting contract, the buyer must allocate a slot to each product in the bundle: exclusive dealing corresponds to a special case in which the number of products in the bundle sold with a slotting contract is equal to $k$. Therefore, the contractual space increases as we move from individual pricing to bundling without slotting contracts and from bundling without slotting contracts to bundling with the permission of slotting contracts.

Our main results are the following. First, under independent pricing, equilibrium often does not exist and hence the outcome is often inefficient. ${ }^{9}$ Second, each firm has an incentive to use bundling instead of independent pricing since bundling reduces competition from rival products. Third, when bundling is allowed, there always exists an efficient equilibrium where each firm uses a technology-renting strategy, regardless of whether or not firms can use slotting contracts. Our technology-renting equilibrium generalizes the marginal cost pricing result ${ }^{10}$ in the literature on competition in non-linear pricing (Armstrong-Vickers, 2001, 2008 and Rochet-Stole 2002) to a situation in which any number of firm can sell any number of products. Furthermore, if all products are digital goods, all equilibria are efficient as long as slotting contracts are prohibited. However, if sellers use slotting contracts, inefficient equilibria can arise even in the case of digital goods. For physical goods, we find

\footnotetext{
${ }^{9}$ Because of the equilibrium non-existence under simultaneous pricing, we consider sequential pricing in a paper (Jeon-Menicucci, 2009) ancillary to this paper: then the equilibrium exists under independent pricing. We characterize it and find that each seller faces a trade-off between quantity (i.e. number of slots to occupy) and extracting surplus per product and that there is no particular reason that this trade-off leads to efficient allocation of slots.

${ }^{10}$ Charging the variable price $(\mathrm{s})$ equal to the (constant) marginal $\operatorname{cost}(\mathrm{s})$ is equivalent to renting the production technology.
} 
a restriction on the sellers' pricing strategies that makes all equilibria efficient. Fourth, we identify portfolio effects of bundling and analyze the implications on horizontal merger. By portfolio effects of bundling, we mean that even though two firms end up selling products of identical values to the buyer, they can realize different profits if their portfolios are different in terms of the products that are not sold. We show that because of the portfolio effects, firms have an incentive to merge. Furthermore, when we make the merger endogenous by considering the auction of a given product, we find that the firm with the strongest portfolio wins the auction, suggesting a tendency of increasing concentration.

One interesting theoretical result is that there is an intermediate level of contractual space such that decreasing or increasing contractual space beyond this level can hurt efficiency. For instance, in the case of digital good, all equilibria are efficient if bundling is allowed and slotting contracts are forbidden. On the one hand, if bundling is forbidden, equilibria may not exist. On the other hand, if bundling and slotting contracts are allowed, inefficient equilibria arise.

To illustrate the incentive to practice bundling, consider a simple example in which firm 1 produces two products of value 3 at zero cost, firm 2 produces one product of value 2 and another product of value zero at zero cost and the buyer has two slots. Suppose that firm 1 wants to sell both products. Then, under independent pricing, each product of firm 1 faces competition from the best product of firm 2 and hence firm 1 realizes a total profit of 2. Consider now bundling. Throughout the paper, in order to determine the price of a given bundle, we first consider the best alternative portfolio that the buyer can build up without buying the bundle and ask how much extra value the buyer can get by improving the portfolio with the purchase of the bundle. Then, without buying the bundle, the best alternative portfolio is composed of only firm 2's products. Instead, if the buyer buys the bundle, she can replace firm 2's products with firm 1's products. This implies that firm 1 can realize a total profit of 4 . This example shows that bundling reduces competition from rival products by changing competition between individual products into competition between portfolios. More precisely, under independent pricing, each product of firm 1 faces competition from the best product of firm 2 but, under bundling, only one product of firm 1 faces competition from the best product of firm 2 and the other product of firm 1 faces competition from the second best product of 2 .

To give the intuition about efficiency under bundling, consider digital goods and assume that slotting contracts are forbidden. Consider a firm owning $m \in[1, k]$ number of products belonging to the $k$ best among all products in the industry. Then the best alternative portfolio that the buyer can build without access to the firm's portfolio includes $m$ products that are inferior to the $m$ products of the firm. Since the buyer can increase her payoff by 
replacing each inferior product with a superior product of the firm, the firm can generate a strictly positive profit from each replacement by selling the bundle of the $m$ products. Therefore, all equilibria are efficient. However, if firms use slotting contracts, inefficient equilibria can arise since if the buyer is bound by slotting contracts, the buyer may not be able to replace an inferior product with a superior one.

Our paper generates clear-cut policy implications (see section 9). In particular, in the case of digital goods, our results suggest that bundling or block booking is good for efficient allocation of slots while slotting contracts (and hence exclusive dealing) are not socially desirable. Furthermore, we also derive policy implications with respect to foreclosure: bundling is unlikely to be a useful instrument for foreclosure (since bundling reduces competition), while slotting contracts can provide a direct instrument of foreclosure.

According to the leverage theory, on which the Supreme Court's decisions to prohibit block booking were based, block booking allows a distributor to extend its monopoly power in a desirable movie to an undesirable one. This theory was criticized by the Chicago School (see e.g. Bowman 1957, Posner 1976, Bork 1978) since the distributor is better off by selling only the desirable movie at a higher price. As an alternative, Stigler (1968) proposed a theory based on price discrimination, ${ }^{11}$ which became a dominant strand (Schmalensee, 1984, McAfee et al. 1989, Shaffer, 1991, Salinger 1995 and Armstrong 1996) at least until Whinston (1990) resuscitated the leverage theory with its first formal treatment (see, for the later work in this line, Choi-Stefanadis 2001, Carlton-Waldman 2002, and Nalebuff 2004). ${ }^{12}$ Basically, in Whinston, tying allows an incumbent to commit to be aggressive, which discourages entry if there is a fixed cost of entry. On the contrary, in our paper, bundling softens competition from rival products and hence it is possible that every firm realizes a (weakly) higher profit when bundling is allowed than when it is prohibited. Then, bundling is unlikely to be an instrument of foreclosure. In section 2, we review Chicago school criticism of the leverage theory and Whinston's revival of the theory and explain how we strengthen Chicago school's arguments.

\footnotetext{
${ }^{11}$ However, Kenney and Klein (1983) point out that simple price discrimination explanation is inconsistent with the facts of Paramount and Loew's and argue that block booking mainly prevents exhibitors from oversearching, (i.e. from rejecting films revealed ex post to be of below-average value). Their hypothesis is empirically tested in a recent paper by Hanssen (2000) but the author finds little support for the hypothesis. But Kenny and Klein (2000) do not agree with Hanseen's analysis.

${ }^{12}$ Armstrong-Vickers (2008) is a bit related to our paper since they consider bundling in a symmetric situation: they study competition between two symmetric firms producing two horizontally differentiated products (i.e. consumers are located in a two-dimensional hotelling space). They find that compared to linear pricing, non-linear pricing has the benefit of efficient variable prices (i.e. marginal cost pricing) but the cost of excessive brand loyalty.
} 
Since each firm can bundle any number of products in our paper, we also contribute to the recent literature on bundling a large number of products. More precisely, in a framework of second-degree price discrimination, Armstrong (1999) and Bakos and Brynjolfsson (1999) show that bundling allows a monopolist to extract more surplus since it reduces the variance of average valuations by the law of large numbers. In our paper, since we assume complete information, the rent extraction issue does not arise in a monopoly setting and the law of large number plays no role. In Jeon-Menicucci (2006), we take a framework similar to the one in the current paper to study bundling electronic academic journals; publishers owning portfolios of distinct journals compete to sell them to a library. The key difference is that competition is generated by the budget constraint of the library instead of the slot constraint. In both papers, we find that bundling is a profitable strategy in terms of surplus extraction. However, contrary to the current paper, Jeon-Menicucci (2006) find that bundling reduces social welfare since if large publishers extract more surplus with bundling, there is less (even zero) budget left for small publishers.

Our efficiency result of bundling is very closely related to the finding in literature on common agency (Bernheim and Whinston (1985, 1986, 1998), O'Brien and Shaffer (1997, 2005)) that shows that when multiple principals deal with a common agent, they can achieve the outcome that maximizes the payoffs of all players. In particular, Bernheim and Whinston (1998) and O'Brien and Shaffer (1997) study the situation when two single-product firms simultaneously offer non-linear tariffs together with exclusive dealing contract to a common retailer and find that the vertically-integrated outcome is obtained. ${ }^{13}$ However, the papers also find other inefficient equilibria and use either the coalition-proof Nash equilibria (Bernheim and Whinston 1986) or Pareto dominance (Bernheim and Whinston 1998 and O'Brien and Shaffer 1997) to select the equilibrium maximizing joint profits. Our contribution is to identify a contracting space (or a condition on contracts) that makes all equilibria efficient in terms of allocation of slots by distinguishing digital goods from physical goods, which allows us to make clear-cut policy implications on bundling and exclusive dealing. Our paper also differs in its focus on comparison between independent pricing and bundling with emphasis on the difference between digital goods and physical goods in a novel setting of competition among portfolios in the presence of slot constraint.

In what follows, section 2 reviews the Chicago School Criticism and the revival of the leverage theory with a simple model and explains our contribution. Section 3 illustrates the key results with a simple example. Section 4 presents the model. Section 5 gives a sufficient condition for equilibrium non-existence under independent pricing. Section 6 presents the

\footnotetext{
${ }^{13}$ O'Brien-Shaffer (2005) show that this result also holds under simultaneous Nash bargaining for the case of $\mathrm{N}$ single-product firms.
} 
main results when firms cannot use slotting contracts. Section 7 studies the situation when firms can use slotting contracts. Section 8 identifies portfolio effects of bundling and studies the implications on horizontal mergers. Section 9 derives policy implications on bundling and slotting contracts in terms of static efficiency and foreclosure and concludes the paper.

\section{Leverage Theory: Criticism and Revival}

According to the leverage theory of tying (or bundling), a multiproduct firm with monopoly power in one market can monopolize a second market using the leverage provided by its monopoly power in the first market. The theory was largely discredited as a result of criticisms originating in the Chicago School (see e.g. Bowman 1957, Posner 1976, Bork 1978) and then was revived by Whinston (1990). In this section, we review both the Chicago School Criticism and Whinston's revival of the leverage theory in a highly stylized model and explain our contribution with respect to them.

\subsection{Chicago School Criticism}

Consider two independent products $(1,2)$ and two sellers $(\mathrm{A}, \mathrm{B})$. A is the monopolist of product 1 and $\mathrm{A}$ and $\mathrm{B}$ compete in the market for product 2. There is a single customer, called $\mathrm{C}$, who has a unit demand for each product. Assume that the cost of production is $c(>0)$ for each product. C's valuation (willingness to pay) for product 1 is $u_{A}^{1}(>c)$ and C's valuation for product 2 produced by $\mathrm{A}(\mathrm{B})$ is $u_{A}^{2}>c\left(u_{B}^{2}>c\right)$. We assume the following incompatibility condition; $c>u_{B}^{2}-u_{A}^{2}$. The assumption means that once $\mathrm{C}$ buys product 2 from $\mathrm{A}, \mathrm{B}$ cannot induce $\mathrm{C}$ to buy his own product without making a loss. In addition, we suppose that $u_{A}^{1}+u_{A}^{2}>u_{B}^{2}+c$, which implies that by bundling his own two products, A can induce $\mathrm{C}$ to buy the bundle and realize a positive profit. We consider a two stage game in which A first decides whether or not to bundle his products, and then A and B compete in prices. In the case of bundling, A offers only the pure bundle: in the example of section 2 , bundling means pure bundling.

In the absence of bundling, seller $i(=\mathrm{A}, \mathrm{B})$ simultaneously chooses a price for product $j(=1,2), p_{i}^{j} \in[c, \infty)$. In equilibrium, A always sells product 1 at $p_{A}^{1}=u_{A}^{1}$ and sells product 2 at $p_{A}^{2}=c+u_{A}^{2}-u_{B}^{2}$ if and only if $u_{A}^{2} \geq u_{B}^{2} \cdot{ }^{14}$ Hence, the profit of A without bundling is given by $u_{A}^{1}-c+\max \left\{0, u_{A}^{2}-u_{B}^{2}\right\}$ and the outcome is always socially efficient.

Suppose now that A bundles his own products and charges $P_{A}$ for the bundle. Then, in equilibrium he succeeds in selling the bundle at $P_{A}=u_{A}^{1}+c+u_{A}^{2}-u_{B}^{2}$, realizing a profit

\footnotetext{
${ }^{14}$ If instead $u_{A}^{2}<u_{B}^{2}$, then B sells his own product 2 at $p_{B}^{2}=c+u_{B}^{2}-u_{A}^{2}$.
} 
of $u_{A}^{1}-c+u_{A}^{2}-u_{B}^{2}$. This implies that the outcome is socially inefficient if $u_{A}^{2}<u_{B}^{2}$.

Comparing A's profit in the two cases of bundling and no bundling, we see that bundling does not affect the profit if $u_{A}^{2} \geq u_{B}^{2}$, but decreases it otherwise. This shows that A never has the incentive to practice bundling for the purpose of monopolizing the tied product market. Furthermore, a laissez-faire policy always achieves social efficiency.

However, we notice that the Chicago School's criticism is a weak argument in a double sense: a social planner never strictly prefers bundling (since the outcome is always socially efficient without bundling but it can be inefficient with bundling) and sellers never have any strict incentive to practice bundling (since a seller can never strictly increase his profit with bundling).

In our paper, we find a strong argument for laissez-faire regarding bundling: in particular, in the case of digital goods (i) if bundling is prohibited, market outcome is often inefficient since equilibrium often does not exist but if bundling is allowed, an efficient equilibrium always exists and all equilibria are efficient (without slotting contracts) (ii) each seller has at least a weak and sometimes a strict incentive to practice bundling. In section 3 , we illustrate these points with a simple example.

\subsection{Revival of the Leverage Theory}

The leverage theory has been revived by Whinston (1990), who points out that the Chicago school argument hinges crucially on the assumption that the tied good market has a competitive constant returns-to-scale structure. He shows that if scale economies exist and the structure of the tied market is oligopolistic, tying can be an effective strategy for a monopolist to extend monopoly power to the tied good market by inducing exit of the rival firm(s).

To present his contribution, we modify the timing as follows: B makes an entry decision after A's bundling/no bundling decision. If B decides to enter the market 2, it must pay a fixed cost of $F$ satisfying $F<u_{B}^{2}-u_{A}^{2}$. The inequality means that if there was no bundling, $\mathrm{B}$ could successfully enter the market 2 . However, $u_{B}^{2}-u_{A}^{2}<u_{A}^{1}-c$ holds from section 2.1 and hence if there was bundling, A would be able to make a positive profit by selling the bundle even if B enters the market. Therefore, pure bundling allows A to foreclose B from the market 2 .

It is important to notice that in Whinston's model, pure bundling induces A to be aggressive. More precisely, after bundling, A can realize a positive profit only if he induces $\mathrm{C}$ to buy the bundle and hence A is ready to undercut B's price up to the point that the price of the bundle reaches $2 c$. However, bundling is not profitable for A once B entered 
the market 2, as $u_{B}^{2}>u_{A}^{2}$. Therefore, A must be able to pre-commit to bundling.

On the contrary, we find that in our static model without fixed cost of entry, bundling is profitable (and hence credible) since it allows to soften competition from rival products. Furthermore, we show that each firm's profit is likely to be (weakly) higher when bundling is allowed than when it is prohibited and therefore bundling is unlikely to be an instrument of foreclosure. In section 3, we illustrate these points with a simple example.

\section{Illustration with a simple example}

We here give a simple example to illustrate some of our main results. There are two sellers, $\mathrm{A}$ and $\mathrm{B}$, and $\mathrm{A}$ has two products with values $\left(u_{A}^{1}, u_{A}^{2}\right)=(4,3)$, while $\mathrm{B}$ has one product of value $u_{B}^{1}=2: u_{i}^{j}$ means the value that the customer, C, obtains from the $j$-th best product among firm $i$ 's products. The values of the products are independent but each product needs to occupy a slot to generate a value and $\mathrm{C}$ has only two slots, which generates competition among the three products. We consider digital goods: the production cost is zero for all products. We note that social efficiency requires that the two slots be occupied by A's two products.

\subsection{Without bundling: non-existence of equilibrium}

Consider a simultaneous pricing game without bundling: seller $i(=\mathrm{A}, \mathrm{B})$ simultaneously chooses a price for product $j(=1,2), p_{i}^{j} \in \mathbf{R}$. We show below that this game has no pure-strategy equilibrium. We assume as a tie-breaking rule that if $\mathrm{C}$ is indifferent among several products, $\mathrm{C}$ buys the products with the highest (gross) values. ${ }^{15}$

First we prove that there is no equilibrium in which A sells only his best product. Indeed, if $\mathrm{A}$ wants to sell only that product, then he can make a profit of 4 by setting $p_{A}^{2}>3$ and $p_{A}^{1}=4,{ }^{16}$ so that $\mathrm{C}$ will not consider buying A's second product but will buy A's first product. B's best response to these prices of 1 is $p_{B}^{1}=2$, and A's profit in this candidate equilibrium is 4 . However, a profitable deviation exists for A: by setting $p_{A}^{1}=3.9$ and $p_{A}^{2}=2.9$, A succeeds in selling his two products and makes a profit of $6.8>4$.

Now we prove that there is no equilibrium in which A sells his two products. In order to sell both products, it is necessary that A sets $p_{A}^{1} \leq 2$ and $p_{A}^{2} \leq 1$, otherwise $4-p_{A}^{1}<2$ and/or $3-p_{A}^{2}<2$, and then $\mathrm{B}$ can profitably sell his own product by charging $p_{B}^{1}>0$ such

\footnotetext{
${ }^{15}$ This tie-breaking rule is standard. See footnote 24 for more details.

${ }^{16}$ Actually, A can make a profit of 4 , by selling a unique product, also by playing $p_{A}^{2}=3$ and $p_{A}^{1}=4$, but in this case we cannot have an equilibrium since there is no best reply for B.
} 
that $2-p_{B}^{1}>\min \left\{4-p_{A}^{1}, 3-p_{A}^{2}\right\}$. This implies that the profit of $\mathrm{A}$ when he sells both products is not larger than 3 . This is inconsistent with an equilibrium, since we have seen above that A can make a profit of 4 by selling only his best product.

In summary, equilibrium does not exist for the following reasons. On the one hand, if A occupies only one slot then he can extract the full surplus of $\mathrm{C}$ from his best product. But then, B's best response is to do the same with his own product, which triggers A's deviation to occupy both slots. On the other hand, if A occupies both slots, each of A's products faces competition from B's product such that A's total profit is lower than the profit he makes from selling only his best product.

\subsection{Bundling}

Suppose now that A offers only a bundle including both of his products at a price $P_{A} \in \mathbf{R}$. For notational consistency, let $P_{B} \in \mathbf{R}$ denote the price that $\mathrm{B}$ charges for his product. In this pricing game, the unique equilibrium is $P_{A}=5, P_{B}=0$ and $\mathrm{C}$ buys A's bundle; thus the outcome is socially efficient. It is easy to see why this is an equilibrium. A has no incentive to charge a higher price, as then $\mathrm{C}$ prefers buying B's product instead of A's bundle. Given that B's profit is zero for any $P_{B} \geq 0, P_{B}=0$ is a best response.

Although this example is simple, it generates useful insights. First, it shows that a firm may have an incentive to use bundling since bundling reduces competition from rival firms' products. To explain this, recall from subsection 3.1 that if A wants to occupy both slots under independent pricing, each of A's products faces competition from B's product and A's profit is at most 3. However, under bundling, A obtains a profit of 5, which is the difference between the gross value of A's bundle (7) and the maximum value $\mathrm{C}$ can obtain without A's bundle (2). Under bundling, it is as if only one product of A faces competition from B's product and the other product of A does not face any competition. The reason why a firm can have a strict incentive to use bundling in our model while it has only a weak incentive in the setup of Chicago school criticism in section 2.1 is that in our model, all three products compete because of the slot constraint while in the setup of section 2.1, A's product 1 does not face any competition from product 2 .

The intuition for why bundling restores efficiency is that when bundling is allowed and sellers sell digital goods, every seller having any number of superior products can make a positive profit by inducing $\mathrm{C}$ to replace each inferior product with a superior one. In order to understand the role of digital goods $(c=0)$, note that the incompatibility condition (i.e. $c>u_{B}^{2}-u_{A}^{2}$ ) is necessary for the leverage through pure bundle à la Whinston to work in section 2. However, for products of heterogenous values (i.e. $u_{B}^{2}>u_{A}^{2}$ in our context), 
this condition is violated as $c$ goes to zero. Then, pure bundle cannot be an instrument of foreclosure. In fact, in the case of digital goods, each firm can find a best response in pure bundling strategies (Lemma 1) (and hence pure bundling is credible) and under competition in pure bundles, the outcome is always efficient (Proposition 3) and each firm's profit is at least weakly and sometimes strictly larger than his profit under independent pricing (Proposition 7), which suggests that pure bundling is unlikely to be an instrument of foreclosure. Therefore, our results imply that block booking of digital goods such as movies is socially desirable.

\section{The Model}

\subsection{The setting}

There are $n$ firms (or sellers), denoted by $i=1, \ldots, n$, and a buyer; we use "he" for each firm and "she" for the buyer; we also use $i=0$ to represent the buyer. Each firm $i(>0)$ has a portfolio of $n_{i}$ distinct products. We use $i j$ to denote firm $i$ 's $j$-th best product (for instance, 12 represents firm 1's 2 nd best product) and $\mathcal{B}_{i}=\left\{i 1, \ldots, i n_{i}\right\}$ represents $i$ 's portfolio of products; let $\mathcal{B} \equiv \mathcal{B}_{1} \cup \ldots \cup \mathcal{B}_{n}$. The buyer has a unit demand for each product and has $k$ $(\geq 1)$ number of slots. A product needs to occupy a slot to generate a value, ${ }^{17}$ and thus the slot's limited availability generates competition among the products. Let $u_{i}^{j}$ be the value that the buyer obtains from allocating a slot to product $i j$; thus $u_{i}^{1} \geq u_{i}^{2} \geq \ldots \geq u_{i}^{n_{i}}>0$ for $i=1, \ldots, n$. We assume that the values are independent: we show at the end of Section 6 that our results hold for substitutes as well. Without loss of generality we assume that each firm's portfolio consists of $k$ products: in the case in which $n_{i} \geq k$, it is straightforward that only the $k$ best products of firm $i$ matter in our setting; in the case of $n_{i}<k$, we define $u_{i}^{n_{i}+1}=\ldots=u_{i}^{k}=0 .{ }^{18}$

With regard to production costs, we assume that a prototype of each product is already produced and the cost of (re)production is $c \geq 0$ for every product $i j \in \mathcal{B}$; ${ }^{19}$ if $c=0$ $(c>0)$, the products are called digital goods (physical goods). Assume for simplicity that

\footnotetext{
${ }^{17}$ By assuming unit demand, we assume for simplicity that a product can occupy at most one slot in that the value generated from occupying a second slot is zero. This assumption can be relaxed without changing the main results.

${ }^{18}$ Even though we consider one buyer, our model can be applied in a straightforward way to a situation with multiple buyers if each buyer operates in a separate market and each seller can price-discriminate the buyers.

${ }^{19}$ The assumption of homogeneous cost is made without loss of generality: at the end of Section 6 we show that the results are (qualitatively) unaffected if this assumption is relaxed.
} 
no cost is incurred by the buyer. ${ }^{20}$ The buyer's payoff is given by the sum of the values of the purchased products minus the prices paid.

Let $u^{j}$ denote the value that the buyer obtains from the $j$-th best product among all products in $\mathcal{B}$; thus $u^{1} \geq u^{2} \geq \ldots \geq u^{n k}$. We assume $u^{k}>u^{k+1}>c$, which implies that the set of the $k$ best products, denoted with $B^{F B}$, is unique and it is socially optimal to occupy all slots with the products in $B^{F B}$. The inequality $u^{k+1}>c$ is assumed because when $u^{k+1} \leq c$, there is no competition among products for slots. For any $B \subseteq \mathcal{B}$, let $U(B)$ represent the total value that the buyer obtains from allocating $k$ slots to the best $k$ products in $B$ : obviously, if $B$ has less than $k$ number of products, the total value is computed by allocating one slot to each product in $B$. In particular, we define $U^{F B} \equiv$ $U\left(B^{F B}\right)=u^{1}+\ldots+u^{k}$. Let $B_{i}^{F B} \equiv B^{F B} \cap \mathcal{B}_{i}$ and let $q_{i}^{F B}$ represent the cardinality of $B_{i}^{F B}$ (hence, $q_{1}^{F B}+\ldots+q_{n}^{F B}=k$ ) while $U_{i}^{F B} \equiv U\left(B_{i}^{F B}\right)=u_{i}^{1}+\ldots+u_{i}^{q_{i}^{F B}}$. Without loss of generality, we assume that there exists $n^{F B}$ between 1 and $n$ such that $q_{i}^{F B} \geq 1$ (that is, $B_{i}^{F B} \neq \emptyset$ ) for $i=1, \ldots, n^{F B}$, and $q_{i}^{F B}=0$ (that is, $B_{i}^{F B}=\emptyset$ ) for $i=n^{F B}+1, \ldots, n$.

In this setup, we study how bundling affects the set of products occupying the buyer's slots. Precisely, we are interested in knowing when the slots are occupied by the products in $B^{F B}$. We say that an equilibrium is (socially) efficient if all slots are allocated to the products in $B^{F B}$ : then the first-best outcome is realized, which is the reason why we use the superscript $F B$.

\subsection{Contracts and games}

In this section, we first describe the bilateral contracts that seller $i$ can propose to the buyer in our model, and then introduce the timing of the games that we study.

\subsubsection{Bundling without slotting contracts}

- Menu of bundles ${ }^{21}$

In the absence of slotting contracts (that will be defined later on), the most general contract between seller $i$ and the buyer is that firm $i$ offers a menu of bundles with prices $\left\{P_{i}\left(B_{i}\right)\right\}_{B_{i} \subseteq \mathcal{B}_{i}}$ : firm $i$ chooses $P_{i}\left(B_{i}\right) \geq 0$ for each $B_{i} \subseteq \mathcal{B}_{i}$, with $P_{i}(\emptyset)=0$. Then, if the buyer buys bundle $B_{1}$ from firm $1, .$. , bundle $B_{n}$ from firm $n$ (some of these sets may be

\footnotetext{
${ }^{20}$ If instead the buyer bears $\operatorname{cost} \gamma_{i}^{j} \geq 0$ to generate a value from product $i j$, then we can consider $u_{i}^{j}-\gamma_{i}^{j}$ as the buyer's gross value and the following analysis applies.

${ }^{21}$ Our definition of menu of bundles generalizes the notion of mixed bundling used in the context of two goods. In this case, mixed bundling means that the seller charges a price for each good and another price for the bundle of both goods.
} 
empty), ${ }^{22}$ then she pays $P_{1}\left(B_{1}\right)+\ldots+P_{n}\left(B_{n}\right)$. Let $s_{i}=\left\{P_{i}\left(B_{i}\right)\right\}_{B_{i} \subseteq \mathcal{B}_{i}}$ denote a generic strategy of firm $i$ and $S_{i}$ be the strategy space for firm $i .^{23}$

- Independent pricing plus a fixed fee

A particular class of menu of bundles is the strategy which is composed of individual prices $\left(p_{i 1}, \ldots, p_{i k}\right)$ and a fixed fee $F_{i} \geq 0$ such that $P_{i}\left(B_{i}\right)=F_{i}+\sum_{i j \in B_{i}} p_{i j}$ for any (nonempty) $B_{i} \subseteq \mathcal{B}_{i}$. In this case, if the buyer wants to buy at least one product from firm $i$, she must first pay $F_{i}$ for the right to buy, and then she pays the individual prices of the products that she selects to buy. Three particular cases of "independent pricing plus a fixed fee" strategies are of great interest:

* Independent pricing: Independent pricing is an extreme case with $F_{i}=0$, thus $P_{i}\left(B_{i}\right)=\sum_{i j \in B_{i}} p_{i j}$ for any $B_{i} \subseteq \mathcal{B}_{i}$.

* Pure bundling: Pure bundling is another extreme case with $p_{i j}=0$ for each $i j \in \mathcal{B}_{i}$ such that $P_{i}\left(B_{i}\right)=F_{i}$ for any $B_{i} \subseteq \mathcal{B}_{i}$. In other words, pure bundling is a deal of all-ornothing.

* Technology-renting: A technology renting strategy consists of two elements: firm $i$ rents his production technology to the buyer by charging $p_{i j}=c$ for each $i j \in \mathcal{B}_{i}$, and extracts (part of) the buyer's surplus by levying a fixed rental fee $F_{i}$. Let $T R_{i}$ be the set of technology-renting strategies, and $t r_{i} \in T R_{i}$ an element of the set. Notice that if $i$ plays a technology renting strategy with fee $F_{i}$, $i$ 's profit is $F_{i}$ if the buyer buys at least one product of $i$, while $i$ 's profit is zero otherwise.

In what follows, we use the word "bundling" for any pricing strategy in menu of bundles which is different from independent pricing.

\subsubsection{Bundling with slotting contracts}

In what follows, we will distinguish two cases depending on whether slotting contracts are used or not. If firm $i$ does not use any slotting contract, the buyer has full freedom in allocating the slots among all products she purchased. In contrast, if the buyer buys from firm $i$ a bundle $B_{i}$ with a slotting contract (and $q_{i}=\# B_{i}$ is the number of products in $B_{i}$ ), the buyer must allocate $q_{i}$ number of slots to the products in $B_{i}$.

- Exclusive dealing

\footnotetext{
${ }^{22}$ In what follows, we simply write that the buyer buys $B_{1} \cup \ldots \cup B_{n}$.

${ }^{23}$ In fact, for some $s_{i} \in S_{i}$, the buyer may want to buy more than one bundle from firm $i$ (for instance, if buying two small bundles is cheaper than buying a big bundle composed of the two small ones). However, none of our arguments or proofs below depends on the assumption that the buyer buys at most one bundle from each firm. Thus, for the sake of simple notation, we make this assumption in the rest of the paper.
} 
Exclusive dealing corresponds to the case in which firm $i$ offers a bundle composed of $k$ products with a slotting contract.

Note that under individual pricing, slotting contracts are redundant since the buyer will not buy any product that will not occupy a slot. In section 6 we study competition among bundles without slotting contracts, and in section 7 we allow for slotting contracts.

\subsection{Timing}

In sections $5-7$, we consider a two-stage pricing game in which

- at stage one, each firm $i$ simultaneously makes a contract offer;

- at stage two, the buyer decides the products (or the bundles) to buy and allocates the slots.

At stage two, as a tie-breaking rule, we assume that in case the buyer is indifferent among different combinations of products, she chooses the combination that maximizes her (gross) value. ${ }^{24}$ We consider only equilibria in pure strategies.

\section{$5 \quad$ Individual pricing}

In this section we consider the case in which each firm uses individual pricing: each firm $i$ chooses $p_{i}^{j}$ for his product with value $u_{i}^{j}$, for $j=1, \ldots, k$; we define $w_{i}^{j} \equiv u_{i}^{j}-p_{i}^{j}$ as the net value of product $i j$, for any $i j \in \mathcal{B}$. In this game it is straightforward to describe the behavior of the buyer: she maximizes her utility by buying the $k$ products with the highest net values, provided that these values are non-negative.

Proposition 1 (independent pricing) When each firm uses individual pricing we find that (i) any equilibrium, if it exists, is efficient.

(ii) Suppose $n^{F B} \geq 2$. If an equilibrium exists, then there exists a number $w^{F B}$ such that $w_{i}^{j}=w^{F B}$ for any $i j \in B^{F B}$, and $w^{F B} \geq u^{k+1}-c(>0)$; hence the profit of firm $i$ is weakly smaller than $U_{i}^{F B}-u^{k+1} q_{i}^{F B}$.

(iii) Suppose $n^{F B} \geq 2$. Suppose also that the product with gross value $u^{k+1}$ is owned by a firm $i^{*}$ such that $B_{i^{*}}^{F B} \neq \emptyset$, and $u^{k+1}-u^{k+2}>c$. Then no equilibrium exists

\footnotetext{
${ }^{24}$ This tie-breaking rule is standard in that it is basically equivalent to the following rule applied to two firms producing a homogenous good with different marginal costs. In Bertrand equilibrium, if the cost differential is not large, both firms charge the price equal to the highest marginal cost and the tie is broken by assuming that all consumers buy the good from the firm with the lower marginal cost.
} 
Proof. See Appendix.

Proposition 1(i)-(ii) describes some properties of equilibria under independent pricing: in any equilibrium the slots are occupied by the products in $B^{F B}$, and the net values of these products are all equal to a common value which is the highest net value among products outside $B^{F B}$ (when these products are priced at $c$ ). On the other hand, Proposition 1(iii) gives a sufficient condition for equilibrium non-existence which has two parts. First, there are at least two firms owning products in $B^{F B}$ and one of these firms owns the $k+1$ st best product; let $i^{*}$ represent the latter firm and $i^{*} j^{*}$ the product. The second part is $u^{k+1}-u^{k+2}>c$ (which is trivially satisfied in the case of digital goods as long as products have heterogenous values), which implies that the product with the highest net value among products outside $B^{F B}$ is product $i^{*} j^{*}$. Then, on the one hand, firm $i^{*}$ has an incentive to charge a price $p_{i^{*} j^{*}}$ larger than $c$, in order to reduce the competitive pressure on his products in $B^{F B}$. On the other hand, when $p_{i^{*} j^{*}}>c$ any rival firm $i \neq i^{*}$ selling a product $i j$ in $B^{F B}$ will choose $u_{i}^{j}-p_{i j}=w_{i}^{j}<u^{k+1}-c$, and this allows firm $i^{*}$ to find a profitable deviation that induces the buyer to replace product $i j$ with product $i^{*} j^{*}$. Furthermore, the example in section 3 shows that equilibrium may not exist even when the firm owning the $k+1$ st best product does not own any product in $B^{F B}$.

\section{Bundling without slotting contracts}

In this section, we study competition among sellers when bundling is allowed but slotting contracts are prohibited. In section 6.1, we first show that each firm has an incentive to practice bundling. In section 6.2, we describe an efficient Nash equilibrium (NE) for any $c \geq 0$. Section 6.3 shows that any NE is efficient if $c$ is small and identifies a sufficient condition to make all equilibria efficient for any $c$. Section 6.4 gives results on profits. Section 6.5 performs robustness checks by considering heterogeneous costs or substitution among products.

\subsection{Incentive to bundle}

We first describe an important property of the technology-renting strategies in the following lemma.

Lemma 1 For any profile $\left(s_{i}, s_{-i}\right)$, let $\pi_{i} \geq 0$ denote the profit of firm $i$ given $\left(s_{i}, s_{-i}\right)$. Then, firm $i$ can make profit $\pi_{i}$ also by playing a technology-renting strategy $\operatorname{tr}_{i} \in T R_{i}$ instead of $s_{i}$, such that the fixed fee $F_{i}$ associated with $t_{i}$ is equal to $\pi_{i}$. 
Proof. See Appendix.

Lemma 1 says that no firm $i$ loses anything by restricting attention to strategies in $T R_{i}$ regardless of the strategies used by other firms. We will often use this result in our proofs. In particular, the lemma implies that each firm has at least a weak incentive to practice bundling. We now provide an example to illustrate a case in which a firm, without bundling, cannot earn the profit that he can achieve with a technology renting strategy.

Example 1 Assume $n=2, c=0, k=3$. Firm 1 has three products with values $(5,3,0)$ and firm 2 has three products with values $(4,1.9,1)$. Suppose that firm 2 uses a technologyrenting strategy with $F_{2}=4$. Then, by Lemma 1 , firm 1 can find a best response among technology-renting strategies, and it turns out that it is optimal to charge $F_{1}=5.1$. If instead firm 1 switches to independent pricing, each of his two best products faces the competition from product 22, and the best firm 1 can do is to sell 11 and 12 at prices $5-1.9=3.1$ and $3-1.9=1.1$, respectively, with a profit of 4.2 which is inferior to 5.1 .

The reason why in Example 1 independent pricing gives firm 1 a smaller profit than a technology-renting strategy is the following. Under independent pricing, each product of firm 1 faces competition from firm 2's second-best product, which does not occupy any slot. This is because, under independent pricing, the buyer has the option of buying (and paying) only one product from firm 1 , and thus 1 cannot induce the buyer to buy both 11 and 12 if he charges prices higher than $5-1.9$ and $3-1.9$, respectively. ${ }^{25}$ In contrast, under bundling (or technology-renting), the buyer needs to pay a fixed fee if he wants to buy at least one product of firm 1; by paying this fee the buyer gets both products of 1 (even though the buyer can use only one of them, it does not allow her to save any payment). Thus 1 can set $F_{1}$ taking into account that if the buyer refuses to pay $F_{1}$, she will consume the products of firm 2 with values 1.9 and 1, which means that the two products of firm 1 compete in aggregate with the aggregate of the second-best and the third-best products of firm 2 ; this allows firm 1 to realize a higher profit: 5.1 is derived from $5+3-1.9-1$. In other words, bundling allows firm 1 to soften competition from rival products.

Lemma 1 and Example 1 together imply

Proposition 2 (incentive to bundle) Each firm has at least a weak and sometimes a strict incentive to practice bundling instead of independent pricing.

\footnotetext{
${ }^{25}$ Since 2 uses a technology renting stategy with $F_{2}=4$, the buyer will rent 2's technology (in order to buy at least product 21), and this makes products 22 and 23 available to the buyer at zero marginal price.
} 


\subsection{An efficient equilibrium}

In this section, we show that an efficient equilibrium exists for any $c \geq 0$; in this equilibrium each firm $i$ uses a technology-renting strategy, and thus we can think that the strategy space for each firm $i$ is given by $[0,+\infty)$, the set of possible values of $F_{i}$.

In this equilibrium, $F_{i}=0$ for $i=n^{F B}+1, \ldots, n$, which means that the profit is zero for each firm without products in $B^{F B}$. For $i=1, \ldots, n^{F B}$, instead, let $\mathcal{B}_{-i}$ represent the set $\cup_{h \neq i} \mathcal{B}_{h}$ of products in the portfolios of firms different from $i$, where $-i$ represents all firms except firm $i$. In order to understand the equilibrium value of $F_{i}$, we need to know the best alternative portfolio of products that the buyer can build up to occupy the slots when she does not buy any product from firm $i$. More precisely, we suppose that the buyer has already rented the technologies of all other firms, and therefore she can buy each product in $\mathcal{B}_{-i}$ at the marginal price $c$. The buyer is considering whether to rent also the technology of firm $i$ (i.e., she views $i$ as the marginal seller), and now we determine the highest $F_{i}$ firm $i$ can charge to induce the buyer to rent $i$ 's technology.

For this purpose, let $u_{-i}^{j}$ represent the value of the $j$-th best product among the products in $\mathcal{B}_{-i}$. Then, if $c=0$ (for instance) the best alternative portfolio when the buyer does not buy any product from $i$ is made by the products with values $\left(u_{-i}^{1}, \ldots, u_{-i}^{k}\right)$. However, if $c>0, u_{-i}^{q}<c$ may hold for some $q \leq k$. Then, the best alternative portfolio is composed of less than $k$ number of products since the buyer will not buy any product with value smaller than $c$. We below describe the best alternative portfolio for any $c$.

Let $B_{-i}^{F B} \equiv B^{F B} \backslash B_{i}^{F B}$ denote the set of the first best products in $\mathcal{B}_{-i}$. Obviously, $B_{-i}^{F B}$ will be included in the best alternative portfolio since every product in $B^{F B}$ has a value larger than $c$. Note also that $B_{-i}^{F B}$ includes exactly $k-q_{i}^{F B}$ number of products. Now let $B_{-i}^{S B}$ represent the subset of the best products in $\mathcal{B}_{-i} \backslash B_{-i}^{F B}$ such that the value of each product in $B_{-i}^{S B}$ is not smaller than $c$ and the cardinality of $B_{-i}^{S B}$, denoted by $q_{-i}^{S B}$, is not larger than $q_{i}^{F B} ; q_{i}^{F B}$ is the number of available slots, after $k-q_{i}^{F B}$ have been occupied by $B_{-i}^{F B}$. Therefore $q_{-i}^{S B}$ is the number in $\left\{0, \ldots, q_{i}^{F B}\right\}$ with the following property:

- if $c>u_{-i}^{k-q_{i}^{F B}+1}$, then $q_{-i}^{S B}=0$;

- if $u_{-i}^{k} \geq c$, then $q_{-i}^{S B}=q_{i}^{F B}$;

- if $u_{-i}^{k-q_{i}^{F B}+1} \geq c>u_{-i}^{k}$, then $q_{-i}^{S B}$ is the number in $\left\{1, \ldots, q_{i}^{F B}-1\right\}$ such that $u_{-i}^{k-q_{i}^{F B}+q_{-i}^{S B}} \geq$ $c>u_{-i}^{k-q_{i}^{F B}+q_{-i}^{S B}+1}$.

From the definition of $B_{-i}^{S B}$, when the buyer does not buy anything from $i$, the best alternative portfolio is given by $B_{-i}^{F B} \cup B_{-i}^{S B}$. Then $U_{-i}^{A} \equiv u_{-i}^{1}+\ldots+u_{-i}^{k-q_{i}^{F B}+q_{-i}^{S B}}$ represents the 
total (gross) value from the best alternative portfolio and $U_{-i}^{S B} \equiv u_{-i}^{k-q_{i}^{F B}+1}+\ldots+u_{-i}^{k-q_{i}^{F B}+q_{-i}^{S B}}$ is the total (gross) value from $B_{-i}^{S B}$. Therefore, without renting $i$ 's technology, the buyer's payoff is the net value she obtains from the best alternative portfolio: $U_{-i}^{A}-c\left(k-q_{i}^{F B}+\right.$ $\left.q_{-i}^{S B}\right)-\sum_{h \neq i} F_{h}$. If the buyer rents also $i$ 's technology, she ends up consuming the first best portfolio, as each product is available to her at a marginal price of $c$, and obtains a payoff equal to $U^{F B}-c k-\sum_{h \neq i} F_{h}-F_{i}$. Firm $i$ wants to choose the highest $F_{i}$ which induces the buyer to rent the technology, namely the $F_{i}$ that makes the two payoffs equal; we denote it with $F_{i}^{*}$ (obviously, a value of $F_{i}$ higher than $F_{i}^{*}$ would induce the buyer not to rent $i$ 's technology).

Precisely, let $t r_{i}^{*}$ denote the technology renting strategy of firm $i$ in which the fixed fee $F_{i}^{*}$ is given by:

$$
\begin{gathered}
F_{i}^{*}=U^{F B}-c k-\left[U_{-i}^{A}-c\left(k-q_{i}^{F B}+q_{-i}^{S B}\right)\right] \\
=U_{i}^{F B}-c q_{i}^{F B}-\left(U_{-i}^{S B}-c q_{-i}^{S B}\right) \text { for } i=1, \ldots, n^{F B} \\
F_{i}^{*}=0 \quad \text { for } i=n^{F B}+1, \ldots, n .
\end{gathered}
$$

As we mentioned above, $F_{i}^{*}$ is equal to the difference between the total value of the first best portfolio (net of the cost of producing it) and the total value of the best alternative portfolio (net of the cost of producing it); for instance, in the case of Digital goods (i.e., $c=0), F_{i}^{*}$ is simply equal to $U^{F B}-U_{-i}^{A}=U_{i}^{F B}-U_{-i}^{S B}$. The value of $F_{i}^{*}$ makes the buyer indifferent between renting $i$ 's technology or not, and thus if each firm $i$ sets $F_{i}=F_{i}^{*}$, the buyer buys all products in $B^{F B}$ and the outcome is efficient.

The next proposition establishes that the profile $\left(t r_{1}^{*}, \ldots, t r_{n}^{*}\right)$ is a Nash equilibrium: We call this equilibrium the technology-renting equilibrium.

Proposition 3 (technology-renting equilibrium) For any $c \geq 0$, there exists a NE in which each firm $i$ uses the technology-renting strategy tr $_{i}^{*}$ and this equilibrium is efficient. In this $N E$, firm $i$ 's profit is $F_{i}^{*}$ for $i=1, \ldots, n$, while the buyer's payoff is $\sum_{i=1}^{n^{F B}}\left(U_{-i}^{S B}-c q_{-i}^{S B}\right) \equiv \pi_{0}^{*}$.

Proof. See the Appendix for the complete proof. We here provide a sketch of the proof. We first show that given $\left(t r_{1}^{*}, \ldots, t r_{n}^{*}\right)$, the buyer buys $B_{i}^{F B}$ for $i=1, \ldots, n^{F B}$. And then we prove that there is no profitable deviation for any firm. For this purpose, from Lemma 1, it is enough to consider firm $i$ 's deviations in the set $T R_{i}$ of technology-renting strategies. Obviously, firm $i$ has no incentive to decrease $F_{i}$ below $F_{i}^{*}$; firm $i$ has no incentive to increase $F_{i}$ above $F_{i}^{*}$ since we show that then the buyer will not buy any product from firm $i$.

Our technology-renting equilibrium to some extent generalizes the marginal cost pricing result in the literature on competition in non-linear pricing (Armstrong-Vickers, 2001, 2008 
and Rochet-Stole 2002) to a situation in which each firm can produce any number of products.

In the technology-renting equilibrium, the buyer builds up the first best portfolio $B^{F B}$ and fills the slots with it. This generates a social surplus equal to $U^{F B}-c k$ which is split among the firms and the buyer as follows: firm $i$ 's profit is $F_{i}^{*}$ for $i=1, \ldots, n$, and the buyer's payoff is $\sum_{i=1}^{n^{F B}}\left(U_{-i}^{S B}-c q_{-i}^{S B}\right)$. Furthermore, $F_{i}^{*}$ can be interpreted in terms of the payment received by seller $i$ in the pivotal Vickrey-Clarke-Groves mechanism. If $q_{i}^{F B}=0$, seller $i$ is not pivotal and hence his payment is zero (i.e. $F_{i}^{*}=0$ ). If instead $q_{i}^{F B}>0$, seller $i$ is pivotal. In his absence, the sum of utilities of all other players is $U_{-i}^{A}-c\left(k-q_{i}^{F B}+q_{-i}^{S B}\right)$. In his presence, the sum of utilities of all other players is $U^{F B}-c\left(k-q_{i}^{F B}\right)$. The difference is $U^{F B}-c\left(k-q_{i}^{F B}\right)-\left[U_{-i}^{A}-c\left(k-q_{i}^{F B}+q_{-i}^{S B}\right)\right]$, which is equal to $F_{i}^{*}+c q_{i}^{F B}$ and makes $i$ realize a profit of $F_{i}^{*}$.

The following example illustrates the technology-renting equilibrium.

Example 2 (Illustration of the technology-renting equilibrium) Consider the case in which $k=2, n=2, c=3$, and

$$
\left(u_{1}^{1}, u_{1}^{2}\right)=(12,8), \quad\left(u_{2}^{1}, u_{2}^{2}\right)=(10,5)
$$

Then $p_{i j}=3, F_{1}^{*}=(12-3)-(5-3)=7$ and $F_{2}^{*}=(10-3)-(8-3)=2$.

\subsection{Efficiency}

In this subsection, we first illustrate a case in which an inefficient equilibrium arises for $c>0$ because of pure bundling. And then we show that (i) all equilibria are efficient for $c$ small enough; (ii) the same result holds for any $c$ if firms are restricted to marginal prices which are not smaller than $c$.

\subsubsection{An inefficient equilibrium}

The game we are considering may have many NE different from $\left(t r_{1}^{*}, \ldots, t r_{n}^{*}\right)$, and some of them can be inefficient as the following example illustrates.

Example 3 (pure bundling and inefficiency) Consider the setting of Example 2: $k=2$, $n=2, c=3$ and

$$
\left(u_{1}^{1}, u_{1}^{2}\right)=(12,8), \quad\left(u_{2}^{1}, u_{2}^{2}\right)=(10,5)
$$


In the following NE, each firm i plays a pure bundling strategy and the buyer buys $\{11,12\}$ rather than $B^{F B}=\{11,21\}$ :

$$
\begin{aligned}
& s_{1} \in S_{1} \text { is such that } F_{1}=11, \quad p_{11}=p_{12}=0 \\
& s_{2} \in S_{2} \quad \text { is such that } F_{2}=6, \quad p_{21}=p_{22}=0 .
\end{aligned}
$$

In the above example, given $\left(s_{1}, s_{2}\right)$, the buyer buys $\mathcal{B}_{1}$ and gets a payoff of 9 . Under pure bundling, firm 1 induces the buyer to buy product 12 even though this product does not belong to $B^{F B}$, and firm 2 is unable to sell the superior product 21 for the two following reasons. First, from the all-or-nothing deal, given that the buyer buys 11, her marginal cost of getting product 12 is $p_{12}=0$. Second, in order not to make a loss, firm 2 must charge a price for 21 at least equal to $c=3$ while the buyer's gain from replacing 12 with 21 is 2 .

\subsubsection{Efficiency for $c$ small}

The previous reasoning regarding example 3 also suggests that the result may be different (i.e., the inefficient equilibrium may disappear) if $c$ were smaller than 2 , as this makes $10-c$ larger than 8 and therefore firm 2 could induce the buyer to replace 12 with 21 and make a positive profit. Indeed, we can prove that if $c<u^{k}-u^{k+1}$ then in any NE the buyer buys $B^{F B}$. This makes the issue of multiplicity not very serious from the point of view of social welfare.

Proposition 4 (efficiency for c small) When bundling is allowed, all Nash equilibria are efficient (i.e., in any NE, the buyer buys the set $B^{F B}$ ) if $c<u^{k}-u^{k+1}$.

Proof. See Appendix.

Proposition 4 holds because of the argument made above regarding Example 3. Suppose that a profile of strategies $\left(s_{1}, \ldots, s_{n}\right)$ induces the buyer to buy $B=B_{1} \cup \ldots \cup B_{n}$ such that product $i j$ belongs to $B^{F B}$ but not to $B$, while product $i^{\prime} j^{\prime}$ belongs to $B$ and not to $B^{F B}$. Then firm $i$ can induce the buyer to buy $B_{i} \cup\{i j\}$ for an extra outlay of $c+\varepsilon$ and to give $i j$ the slot previously assigned to $i^{\prime} j^{\prime}$, since the buyer increases her profit by $u_{i}^{j}-c-\varepsilon-u_{i^{\prime}}^{j^{\prime}}$, and $u_{i}^{j}-u_{i^{\prime}}^{j^{\prime}}>c$ because $u^{k}-u^{k+1}>c$. Notice that this argument does not require that the buyer stops buying product $i^{\prime} j^{\prime}$, since $P_{i^{\prime}}\left(B_{i^{\prime}} \backslash\left\{i^{\prime} j^{\prime}\right\}\right)$ may be larger than $P_{i^{\prime}}\left(B_{i^{\prime}}\right){ }^{26}$

\footnotetext{
${ }^{26}$ We are using the free disposal assumption, which makes sense in this section where there is no slotting contract. In the next section where the buyer can sign slotting contracts, free disposal is still assumed as long as it does not violate the slotting contracts signed by the buyer.
} 
It is very interesting to note the similarity between the condition $c<u^{k}-u^{k+1}$ in Proposition 4 that makes all equilibria efficient under bundling and the condition $c<$ $u^{k+1}-u^{k+2}$ in Proposition 1(iii) that makes equilibrium not exist under independent pricing. In particular, in the case of digital goods, both conditions are trivially satisfied as long as products have heterogenous values. Then, allowing bundling changes the market outcome dramatically from non-existence of equilibrium to "all market outcomes are efficient".

Next, we give a simple corollary of Proposition 4:

Corollary 1 In the case of digital goods,

(i) if bundling is forbidden, as long as the firm owning the $k+1$ st best product owns a product in $B^{F B}$ (and there is no monopoly of $B^{F B}$ ), no equilibrium exists;

(ii) if bundling is allowed, at least one equilibrium exists and all equilibria are efficient. Therefore a policy of laissez-faire regarding bundling achieves efficiency.

The corollary has an important policy implication. In the case of digital goods, when bundling is allowed, each firm has an incentive to practice bundling (proposition 2), at least one equilibrium exists (Proposition 3), and all equilibria are efficient (Proposition 4). Therefore, we can conclude that in the case of digital goods, a policy of laissez-faire achieves efficiency.

\subsubsection{Achieving efficiency for $c$ not small}

Example 3 shows that inefficient equilibria can exist for $c$ large. In this section, we show that efficiency holds in any equilibrium if firms are prohibited from setting the marginal price $^{27}$ of any product below its cost $c$. Precisely, we consider the following restriction for firm $i$ 's strategies:

$$
\begin{gathered}
\text { for any } i j \in \mathcal{B}_{i} \text { and any } B_{i} \subset \mathcal{B}_{i} \text { such that } i j \notin B_{i} \\
\qquad P_{i}\left(B_{i} \cup\{i j\}\right)-P_{i}\left(B_{i}\right) \geq c \text { for } i=1, \ldots, n .
\end{gathered}
$$

The meaning of (2) is that as the number of objects in a bundle of firm $i$ increases, the price of the bundle needs to increase at least by the cost of the additional products in the bundle. As a consequence, if firm $i$ is interested in selling a particular bundle $B_{i}$ for a certain price $P^{*}$, condition (2) forces him to make each subset of $B_{i}$ available at a price strictly (weakly) smaller than $P^{*}$ if $c>0$ (if $c=0$ ) such that the buyer can save at least $c$ by cancelling a product within $B_{i}$. In particular, the condition makes it impossible for

\footnotetext{
${ }^{27} \mathrm{By}$ the marginal price we mean the increase in the price of a bundle when an additional product is added to the bundle.
} 
a firm to use the pure bundling strategy (i.e., to propose only a single bundle by charging only a fixed fee) for $c>0$. Note that an "independent pricing plus fixed fee" strategy satisfies (2) if and only if $p_{i j} \geq c$ for any $i j$ (i.e., if each individual price is larger than the cost) and in particular every technology-renting strategy satisfies (2). Thus, from Lemma 1 we know that firm $i$ can find a best response to $s_{-i}$ in the set of strategies satisfying (2), for any $s_{-i}$.

Under the restriction (2) we can show that all the NEs are efficient for any $c{ }^{28}$

Proposition 5 (efficiency for any c) Suppose that each firm must satisfy (2). Then, all equilibria are efficient for any $c \geq 0$.

Proof. See Appendix.

The intuition for the efficiency result of Proposition 5 is somewhat linked to the intuition for Proposition 4. Suppose that a profile of strategies $\left(s_{1}, \ldots, s_{n}\right)$ induces the buyer to buy $B=B_{1} \cup \ldots \cup B_{n}$ such that product $i j$ belongs to $B^{F B}$ but not to $B$, while product $i^{\prime} j^{\prime}$ belongs to $B$ and not to $B^{F B}$. When (2) holds, firm $i$ can increase his profit by inducing the buyer to replace $i^{\prime} j^{\prime}$ with $i j$ (with the latter product priced marginally at $c+\varepsilon$ ) because cancelling $i^{\prime} j^{\prime}$ allows the buyer to save at least $c$, and thus the buyer earns at least $u_{i}^{j}-(c+\varepsilon)-\left(u_{i^{\prime}}^{j^{\prime}}-c\right)>0$ from replacing $i^{\prime} j^{\prime}$ with $i j$.

Remark 1: In the practice of competition policy, firms' charging prices below cost have been discussed in the context of predation: Areeda and Turner (1975) were the first to propose to use pricing below costs to identify predation. Our model does not deal with predation, but interestingly Proposition 5 shows that prohibiting firms from charging individual prices (or marginal prices) below costs makes all equilibria efficient in our static pricing game.

\subsection{Profits}

In this subsection, we study sellers' payoffs under bundling and then study how bundling affects profits. For the first part, we have:

Proposition 6 (profits) When bundling is allowed;

(i) In the case of digital goods, in any equilibrium firm $i$ realizes at least a profit of $F_{i}^{*}$, the profit in the technology-renting equilibrium, for $i=1, \ldots, n$.

(ii) When $n=2$, in any $N E$ the profit of firm $i$ is not larger than $F_{i}^{*}$, for $i=1,2$.

\footnotetext{
${ }^{28}$ Not surprisingly, condition (2) is violated by the strategy of firm 1 in example 3 .
} 
(iii) When $n=2$ and each firm must satisfy (2), in any NE the profit of firm $i$ is equal to $F_{i}^{*}$, for $i=1,2$.

Proof. See Appendix.

Proposition 6(i) is straightforward since when $c=0$, firm $i$ certainly makes profit $F_{i}^{*}$ by playing the technology renting strategy with $F_{i}=F_{i}^{*}$, independently of the strategies played by the other firms. Indeed, even though the other firms were to give away their products for free (the worst case for firm $i$ ), the buyer would be still willing to pay $F_{i}^{*}=U_{i}^{F B}-U_{-i}^{S B}$ to replace the products in $B_{-i}^{S B}$ with the products in $B_{i}^{F B}$.

The intuition for proposition 6 (ii) is that when $n=2, F_{1}^{*}$ makes the buyer indifferent between buying $B_{1}^{F B}$ from 1 (at the marginal price $c q_{1}^{F B}$ ) and buying $B_{-1}^{S B}$ from 2 (at the marginal price $c q_{-1}^{S B}$ ). Then, if 1 attempts to make a profit larger than $F_{1}^{*}, 2$ can increase his profit by inducing the buyer to buy $B_{-1}^{S B}$ at a price a bit higher than $c q_{-1}^{S B}$. Furthermore, when each firm is required to charge a marginal price larger than or equal to $c$, we can pin down the equilibrium profit of each firm and show that it is equal to $F_{i}^{*}$.

Propositions 4, 5, and 6 imply

Corollary 2 Suppose that $n=2$.

(i) The technology-renting equilibrium Pareto dominates any other equilibrium in terms of sellers' payoffs.

(ii) In the case of digital goods or when each firm must satisfy (2), in all equilibria the outcome is identical to that of the technology-renting equilibrium in terms of allocation of slots and of each player's payoff.

Not surprisingly, each seller's profit is lower in the inefficient equilibrium of example 3 than in the technology-renting equilibrium of example 2.

Remark 2: Corollary 2(i) is similar to the finding of Bernheim and Whinston (1998) and O'Brien and Shaffer (1997) that Pareto undominated equilibria maximize the joint payoffs of all sellers and the (single) buyer.

Remark 3: For $n>2$, it is more difficult to pin down each firm's equilibrium profit. When all firms are required to satisfy (2), we can show that firm $i$ can realize at least a profit equal to $F_{i}^{*}$ (in fact, this is proven in the proof of Proposition 6(iii) for an arbitrary $n \geq 2$ ); but we have been unable to establish that $F_{i}^{*}$ is also an upper bound for the profit of firm $i$.

We now study how bundling affects profits. 
Proposition 7 (profit comparison) Assume that $n^{F B} \geq 2$ and that an equilibrium exists under independent pricing.

(i) Each seller i's profit under independent pricing is weakly smaller than $F_{i}^{*}$.

(ii) For any seller $i=1, \ldots, n^{F B}$, his profit under independent pricing is strictly smaller than $F_{i}^{*}$ unless $u^{k+1}=u_{-i}^{k-q_{i}^{F B}+1}=\ldots=u_{-i}^{k}$ holds.

Proof. From Proposition 1(ii), we know that the profit of firm $i$ (for $i \leq n^{F B}$ ) has an upper bound given by $U_{i}^{F B}-u^{k+1} q_{i}^{F B}$. Furthermore,

$$
F_{i}^{*}=U_{i}^{F B}-c q_{i}^{F B}-\left(U_{-i}^{S B}-c q_{-i}^{S B}\right) \geq U_{i}^{F B}-c q_{i}^{F B}-\left(u^{k+1}-c\right) q_{i}^{F B}=U_{i}^{F B}-u^{k+1} q_{i}^{F B}
$$

where the inequality comes from the fact that $\left(u^{k+1}-c\right) q_{i}^{F B} \geq U_{-i}^{S B}-c q_{-i}^{S B}$ holds because $U_{-i}^{S B}=u_{-i}^{k-q_{i}^{F B}+1}+\ldots+u_{-i}^{k-q_{i}^{F B}+q_{-i}^{S B}}, q_{-i}^{S B} \leq q_{i}^{F B}$, and $u^{k+1} \geq u_{-i}^{k-q_{i}^{F B}+1} \geq \ldots \geq u_{-i}^{k-q_{i}^{F B}+q_{-i}^{S B}}$. This proves that the inequality is satisfied strictly unless $u^{k+1}=u_{-i}^{k-q_{i}^{F B}+1}=\ldots=u_{-i}^{k}$ holds.

Proposition 1(i)-(ii) show that if an equilibrium exists under independent pricing, it is efficient and each product of $i$ which is sold faces competition from the best product in $\mathcal{B} \backslash B^{F B}$. As we already noticed, bundling changes competition among individual products into competition among portfolios: now $B_{i}^{F B}$ competes with $B_{-i}^{S B}$. Therefore, unless all products in $B_{-i}^{S B}$ have the same value equal to $u^{k+1}$, bundling strictly increases $i$ 's profit for firm $i=1, \ldots, n^{F B}$.

\subsection{Robustness}

In this subsection, we perform two robustness checks.

\subsubsection{The case of heterogenous costs}

We can show that our notation can be modified to extend all the previous results in this section to the case in which production costs are heterogenous, that is the production cost of firm $i$ for product $i j$ is $c_{i}^{j} \geq 0$. For this purpose, we define $v_{i}^{j}=u_{i}^{j}-c_{i}^{j}$ as the value of product $i j$ net of production cost and order products of firm $i$ according to these net values such that $v_{i}^{1} \geq v_{i}^{2} \geq \ldots \geq v_{i}^{k}$. We use $v^{j}$ and $v_{-i}^{j}$ to denote the value of the $j$-th best product among all products in $\mathcal{B}$ or in $\mathcal{B}_{-i}$, respectively, and we suppose that $v^{k}>v^{k+1}>0$. For $B \subseteq \mathcal{B}$, let $V(B)$ represent the total net value that the buyer obtains from allocating the slots to the $k$ products with highest net value in $B$ (if $\# B \geq k$ ), when she pays the production cost for each such product. Let $V^{F B} \equiv V\left(B^{F B}\right)$ and $B_{-i}^{F B} \equiv B^{F B} \backslash B_{i}^{F B}$, a set which includes exactly $k-q_{i}^{F B}$ number of products. Now let $B_{-i}^{S B}$ represent the subset of 
the best products in $\mathcal{B}_{-i} \backslash B_{-i}^{F B}$ such that the net value of each product in $B_{-i}^{S B}$ is not smaller than 0 and the cardinality of $B_{-i}^{S B}$, denoted by $q_{-i}^{S B}$, is not larger than $q_{i}^{F B}$. Therefore $q_{-i}^{S B}$ is the number in $\left\{0, \ldots, q_{i}^{F B}\right\}$ with the following property:

- if $0>v_{-i}^{k-q_{i}^{F B}+1}$, then $q_{-i}^{S B}=0$;

- if $v_{-i}^{k} \geq 0$, then $q_{-i}^{S B}=q_{i}^{F B}$;

- if $v_{-i}^{k-q_{i}^{F B}+1} \geq 0>v_{-i}^{k}$, then $q_{-i}^{S B}$ is the number in $\left\{1, \ldots, q_{i}^{F B}-1\right\}$ such that $v_{-i}^{k-q_{i}^{F B}+q_{-i}^{S B}} \geq$ $0>v_{-i}^{k-q_{i}^{F B}+q_{-i}^{S B}+1}$.

A technology renting strategy for firm $i$ is defined as $p_{i j}=c_{i}^{j}$ for $j=1, \ldots, k$ together with $F_{i}$, and Lemma 1 holds. Proposition 3 holds with $F_{i}^{*}=V^{F B}-V_{-i}^{A}$, where $V_{-i}^{A} \equiv$ $V\left(B_{-i}^{F B} \cup B_{-i}^{S B}\right)$. Proposition 4 holds if $v^{k}>\max _{i j \in \mathcal{B} \backslash B^{F B}} u_{i}^{j}$ and Proposition 5 holds under the restriction $P_{i}\left(B_{i} \cup\{i j\}\right)-P_{i}\left(B_{i}\right) \geq c_{i}^{j}$.

\subsubsection{The case of substitutes}

In this subsection we consider substitution among products. Since it is hard to describe all possible substitutions for every possible subset of $\mathcal{B}$, we consider a simple case of substitution and show that our results are robust. Precisely, we assume that if the buyer buys the set of products $B \subseteq \mathcal{B}$ with $q=\#(B)$, then there is a number $s>0$ such that her gross utility from the products in $B$ is given by $U(B)-(q-1) s$, and $s$ is small enough to satisfy $u^{k+1}-s>c$. With this subadditive utility function we represent a negative synergy which has a constant magnitude as the number of products used by the buyer increases.

Our previous results in this section hold to this setting provided that we replace $u_{i}^{j}$ with $\tilde{u}_{i}^{j} \equiv u_{i}^{j}-s$ for each $i$ and $j$. Indeed, let $\tilde{U}(B)$ be defined as $U(B)$ in which $\tilde{u}_{i}^{j}$ replaces $u_{i}^{j}$. Then it is simple to see that $U(B)-(q-1) s=\tilde{U}(B)+s$. In other words, the buyer's

gross utility from bundle $B$ is given by $\tilde{U}(B)$, except for the constant $s$. Then everything happens as if the value of each product has been reduced by $s$, and thus the technology renting equilibrium still exists, albeit with different fixed fees. As a general result we find that both the firms and the buyer make (weakly) lower profits in this equilibrium than when $s=0$; the driving force for this result is that the social value which is generated by trade is lower because of the substitution. In particular, the buyer's profit is strictly reduced. The profit of each firm $i=1, \ldots, n^{F B}$ is also reduced, unless $q_{i}^{F B}=q_{-i}^{S B}$ and $u_{-i}^{k}-s \geq c$. Finally, the results about efficient equilibria are unchanged by the negative synergy. 


\section{$7 \quad$ Bundling with slotting contracts}

In this section we study a setting in which each firm $i$ can use slotting contracts. When firm $i$ uses slotting contracts, buying a bundle $B_{i}$ requires the buyer to allocate slots to all products in $B_{i}$; therefore, if all firms use slotting contracts, the buyer can buy $B_{1} \cup \ldots \cup B_{n}$ only if $\#\left(B_{1} \cup \ldots \cup B_{n}\right) \leq k$. By using slotting contracts, it may be possible (and profitable) for firm $i$ to induce the buyer to buy a bundle bigger than $B_{i}^{F B}$, in order to make sales of the rival firms difficult. In extreme cases, $i$ may succeed in occupying all slots with his own products by setting $P_{i}\left(B_{i}\right)$ very high for each $B_{i} \neq \mathcal{B}_{i}$ and choosing $P_{i}\left(\mathcal{B}_{i}\right)$ to induce the buyer to buy $\mathcal{B}_{i}$, as it occurs in the following example.

Example 4 (slotting contracts and inefficiency) Suppose that $n=2, k=3, c=0$, and

$$
\left(u_{1}^{1}, u_{1}^{2}, u_{1}^{3}\right)=(10,7,6) ; \quad\left(u_{2}^{1}, u_{2}^{2}, u_{2}^{3}\right)=(9,8,1)
$$

Here $B^{F B}=\{11,21,22\}$, so that $q_{1}^{F B}=1$ and $q_{2}^{F B}=2$. However, there exists an inefficient $N E$ in which $P_{i}\left(B_{i}\right)$ is high enough for each $B_{i} \neq \mathcal{B}_{i}$, for $i=1,2$, and $P_{1}\left(\mathcal{B}_{1}\right)=5$, $P_{2}\left(\mathcal{B}_{2}\right)=0$. In words, each firm $i$ offers only $\mathcal{B}_{i}$ through a slotting contract, and Bertrand competition between $\mathcal{B}_{1}$ and $\mathcal{B}_{2}$ determines the above prices. In this $N E$, firm 1 occupies the three slots even though products 21 and 22 are both better than 12 and 13.

This example shows that even in the case of digital goods, inefficient equilibria exist when firms can use slotting contracts; this contrasts with Proposition 4, which shows that efficiency is always achieved for small values of $c$ without slotting contracts. The reason for why such a result does not hold with slotting contracts is that a firm $i$ with a product ij $\in B^{F B}$ may not be able to induce the buyer to modify her portfolio by replacing an inferior product of a rival firm with product $i j$, even though firm $i$ charges a very small price, in case the rival firm uses a slotting contract. Indeed, all three products of firm 1 are bounded with the slotting contract such that replacing for instance product 13 with product 21 implies that the buyer cannot use any product of firm 1, which is unprofitable for the buyer. On the contrary, without slotting contracts, after buying $\mathcal{B}_{1}$, the buyer can freely dispose of any product in $\mathcal{B}_{1}$ to replace it with a superior product.

In spite of Example 4, we can show that Lemma 1 holds and the technology-renting equilibrium described by Proposition 3 is a NE also under slotting contracts and thus an efficient NE always exists in this setting. Furthermore, also Propositions 5 and 6 hold in this environment.

Corollary 3 Regardless of whether each firm can use slotting contracts or not, 
(i) a firm can find a best response among technology-renting strategies without using slotting contracts;

(ii) there exists a technology-renting equilibrium: the profile $\left(t r_{1}^{*}, \ldots, t r_{n}^{*}\right)$ described in (1) is a $N E$ for any $c \geq 0$;

(iii) every $N E$ is efficient under condition (2);

(iv) if $n=2$, the technology-renting equilibrium Pareto dominates any other NE.

Proof. For the proof of (i) we can follow the proof of Lemma 1 to show that - given a profile of strategies of other firms - firm $i$ does not lose anything from using a suitable technology renting strategy without the clause of slotting contracts. For the proof of (ii)(iv), we notice that in the proofs of Proposition 3,5 and 6(ii) we never use the possibility that the buyer does not allocate a slot to a product she has purchased. In other words, in the equilibria of Proposition 3,5 and 6(ii), the buyer buys only the products that she will use. This differs from the proof of Proposition 4, which indeed does not apply under slotting contracts, as Example 4 proves.

Corollary 3(iii) suggests that if firms are prohibited from charging marginal prices below costs, all equilibria are efficient regardless of whether they can use slotting contracts. This result is not surprising since, as we said in subsection 6.3.3, condition (2) makes pure bundling impossible and, when a firm offers a bundle, forces each firm to offer a complete subset of the bundle as well. ${ }^{29}$ This in turn allows the buyer to buy only the products that would occupy a slot and makes slotting contracts redundant.

While corollary 3(iv) holds for duopoly, the following example shows that there can be a Pareto undominated inefficient equilibrium if there are more than two firms.

Example 5 (slotting contracts and Pareto undominated inefficient equilibria). Suppose that $n=3, k=3, c=0$, and

$$
\left(u_{1}^{1}, u_{1}^{2}, u_{1}^{3}\right)=(10,7,6) ; \quad\left(u_{2}^{1}, u_{2}^{2}, u_{2}^{3}\right)=\left(u_{3}^{1}, u_{3}^{2}, u_{3}^{3}\right)=(9,8,1)
$$

Here $B^{F B}=\{11,21,31\}$ and $q_{1}^{F B}=1, F_{1}^{*}=2$. However, there exists an inefficient equilibrium in which each firm $i$ proposes only the bundle $\mathcal{B}_{i}$ of all his products and uses the slotting contract. Prices are $P_{1}\left(\mathcal{B}_{1}\right)=5, P_{2}\left(\mathcal{B}_{2}\right)=0, P_{3}\left(\mathcal{B}_{3}\right)=0$. In this equilibrium, firm 1 occupies all slots and his profit is $5\left(>F_{1}^{*}\right)$.

\footnotetext{
${ }^{29}$ Our condition (2) to some extent formalizes the conjecture of Bernheim-Whinston (1986) that inefficient equilibria would disappear if every bidder (seller) makes a serious bid (price offer) on all possible allocations (subsets of his portfolio).
} 


\section{Portfolio effects of Bundling}

In this section, we identify portfolio effects of bundling and analyze the consequences on a horizontal merger. For this purpose, we focus our discussion on the technology-renting equilibrium in which each seller $i$ makes a profit of $F_{i}^{*}$.

\subsection{Portfolio effects}

Proposition 1(ii) shows that under independent pricing, all products sold give the same net values to the buyer. This implies that two products of identical values must be sold at the same prices. This is not necessarily the case with bundling because of portfolio effects. By portfolio effects of bundling, we mean that two firms who end up selling products with the same values can make different profits. Consider the setting with digital goods for simplicity, and suppose that firms 1 and 2 are such that $q_{1}^{F B}=q_{2}^{F B}$ and $u_{1}^{j}=u_{2}^{j}$ for $j=1, \ldots, q_{1}^{F B}$, but $u_{1}^{j}>u_{2}^{j}$ for $j=q_{1}^{F B}+1, \ldots, k$. Then, we have $U_{1}^{F B}=U_{2}^{F B}$ and $U_{-1}^{S B} \leq U_{-2}^{S B}$, which implies

$$
F_{1}^{*}=U_{1}^{F B}-U_{-1}^{S B} \geq F_{2}^{*}=U_{2}^{F B}-U_{-2}^{S B} .
$$

In addition, if $B_{-1}^{S B} \cap \mathcal{B}_{2} \neq \phi$ then $U_{-1}^{S B}<U_{-2}^{S B}$ and thus $F_{1}^{*}>F_{2}^{*}$ : the buyer ends up purchasing products of identical values from both firms but pays a higher price to firm 1. This is because in equilibrium each firm $i$ extracts with $F_{i}^{*}$ the surplus that the buyer obtains by replacing the products belonging to $B_{-i}^{S B}$ with the products belonging to $B_{i}^{F B}$. From another point of view, $F_{i}^{*}$ can also be written as $F_{i}^{*}=U^{F B}-U_{-i}^{A}$ and $U^{F B}$ is the same for all firms while $U_{-i}^{A}$ is smaller for firms with better portfolios.

Corollary 4 (portfolio effects) Bundling generates portfolio effects, which do not exist under independent pricing. More precisely, suppose that firms 1 and 2 are such that $q_{1}^{F B}=q_{2}^{F B}$ and $u_{1}^{j}=u_{2}^{j}$ for $j=1, \ldots, q_{1}^{F B}$, but $u_{1}^{j}>u_{2}^{j}$ for $j=q_{1}^{F B}+1, \ldots, k$. Then, in the technologyrenting equilibrium, the buyer buys products of identical values from both firms (i.e., $B_{1}^{F B}$ from 1 and $B_{2}^{F B}$ from 2) but pays $F_{1}^{*} \geq F_{2}^{*}$. In addition, if $B_{-1}^{S B} \cap \mathcal{B}_{2} \neq \phi$, then $F_{1}^{*}>F_{2}^{*}$.

\subsection{Portfolio effects and horizontal merger}

A natural and important consequence of the portfolio effects is that it creates incentives for a horizontal merger. We will first consider a merger between two given firms and then make the merger endogenous.

Consider the merger of any two firms $i$ and $h$ (with $i \neq h$ ) and let the two firms after the merger be denoted by $i+h$. 
Proposition 8 (exogenous merger) Consider the merger of any two firms $i$ and $h$.

(i) The merger affects neither social welfare nor any other firm's profit.

(ii) The merger weakly increases the merging firms' profit, and hence weakly decreases the buyer's payoff.

In case $q_{i}^{F B} \geq 1$ and $q_{h}^{F B} \geq 1$, the merger strictly increases the merging firms' profit, and hence strictly decreases the buyer's profit, unless $\max \left\{u_{-i}^{k-q_{i}^{F B}+1}-c, 0\right\}=\max \left\{u_{-h}^{k-q_{h}^{F B}+1}-\right.$ $c, 0\}=\max \left\{u_{-(i+h)}^{k}-c, 0\right\}$.

In case $q_{i}^{F B} \geq 1$ and $q_{h}^{F B}=0$, the merger strictly increases the merging firms' profit if and only if $u_{h}^{1}>\max \left\{c, u_{-i}^{k+1}\right\}$.

Proof. See Appendix.

Social welfare is not affected by the merger since the buyer buys the products in $B^{F B}$ regardless of the market structure of the sellers. The profit of a firm $i^{\prime}$ different from $i$ and $h$ is not affected by the merger since the profit of $i^{\prime}$ is the difference between the value of the best portfolio $B^{F B}$ and the value of the best alternative portfolio $B_{-i^{\prime}}^{F B} \cup B_{-i^{\prime}}^{S B}$ that the buyer can build up without buying any product from firm $i^{\prime}$. Since the composition of both $B_{-i^{\prime}}^{F B}$ and $B_{-i^{\prime}}^{S B}$ is not affected by the merger, the merger does not change the profit of any third firm.

The merger is profitable since it weakens the best alternative portfolio. Before the merger, if the buyer does not buy any product from $i$, the best alternative portfolio may include products from $h$. In contrast, after the merger, the best alternative portfolio does not include products from $h$, which implies that after the merger firm $i+h$ faces a weaker competition than the one faced by firm $i$ before the merger (and also a weaker competition than the one faced by firm $h$ before the merger). This allows the merged firm to command a higher price than the sum of the pre-merger prices of $i$ and $h$.

The conditions in the proposition under which the merger does not increase the profits of the merging firms are very stringent. For instance, when $q_{i}^{F B} \geq 1$ and $q_{h}^{F B} \geq 1$, then the condition holds only in the two following cases. The first case occurs when $u_{-i}^{k-q_{i}^{F B}+1} \leq c$ and $u_{-h}^{k-q_{h}^{F B}+1} \leq c$. Then $u_{-(i+h)}^{k-q_{i}^{F B}-q_{h}^{F B}+1} \leq c$ holds and thus neither firm $i$ nor firm $h$ faces any competition, implying that firm $i+h$ does not face any competition either. Thus $U_{i}^{F B}-c q_{i}^{F B}$ and $U_{h}^{F B}-c q_{h}^{F B}$ are the profits of $i$ and $h$ before the merger while $i+h$ earns $U_{i+h}^{F B}-c q_{i+h}^{F B}=U_{i}^{F B}+U_{h}^{F B}-c\left(q_{i}^{F B}+q_{h}^{F B}\right)$. The second case arises when $u_{-i}^{k-q_{i}^{F B}+1}=u_{-h}^{k-q_{h}^{F B}+1}=u_{-(i+h)}^{k}=u$ for some $u \geq c$. In this case, $i+j$ faces as fierce competition as $i$ and $h$ face separately, and the profits of $i, h$ and $i+h$ are respectively $U_{i}^{F B}-u q_{i}^{F B}, U_{h}^{F B}-u q_{h}^{F B}$, and $U_{i+h}^{F B}-u q_{i+h}^{F B}=U_{i}^{F B}+U_{h}^{F B}-u\left(q_{i}^{F B}+q_{h}^{F B}\right)$.

We now make the merger endogenous in the following way. Suppose that a given firm $h$ sells a product in his portfolio with value $u>c$ for some exogenous reasons. We determine 
the value that each firm $i(\neq h)$ attaches to acquiring this product. From proposition 8 , as any merger does not affect a third firm's profit, if a firm different from firm $i$ buys the product, then firm $i$ 's profit is unchanged with respect to the profit before the sale. If instead firm $i$ buys the product, then his profit increases only when the product belongs to $B_{-i}^{F B} \cup B_{-i}^{S B}$ : in this case, the profit of $i$ increases by $u-\max \left\{u_{-i}^{k+1}, c\right\}$. For instance, if $u_{-i}^{k+1} \geq$ $c, i$ 's purchase of $h$ 's product will modify the best alternative portfolio that the buyer can build up when she does not buy any product from $i$ such that in the portfolio, the product bought from $h$ is replaced by a product with value $u_{-i}^{k+1}$ and hence $B_{-i}^{F B} \cup U_{-i}^{S B}$ is reduced by $u-u_{-i}^{k+1}$, which increases $i$ 's profit by $u-u_{-i}^{k+1}$. If $u_{-i}^{k+1}<c$, the product bought from $h$ simply disappears in the best alternative portfolio and therefore $U_{-i}^{F B}+U_{-i}^{S B}-c q_{-i}^{F B}-c q_{-i}^{S B}$ is reduced by $u-c$, so that $i$ 's profit increases by $u-c$.

If we assume that firm $h$ uses a second price auction, we get the following result.

Proposition 9 Suppose that firm $h$ sells a product in his portfolio with value $u(>c)$ through a second-price auction.

(i) The only undominated bid $b_{i}$ of firm $i$ is

$$
b_{i}=\left\{\begin{array}{cc}
u-\max \left\{u_{-i}^{k+1}, c\right\}, & \text { if } u>u_{-i}^{k+1} \\
0, & \text { otherwise }
\end{array}\right.
$$

(ii) If there is a firm (say firm 1) whose portfolio dominates each other firm's one in the sense that $q_{1}^{F B} \geq q_{i}^{F B}$ and $u_{1}^{q_{1}^{F B}+j} \geq u_{i}^{q_{1}^{F B}+j}$ for $j=1,2, \ldots, k-q_{1}^{F B}$ and for $i=2, \ldots, n$, then $b_{1} \geq b_{i}$ for $i=2, \ldots, n$. Therefore, there is a tendency of increasing concentration.

Proof. See Appendix.

Proposition 9(ii) suggests that there is a tendency of increasing concentration since the dominating firm has a higher willingness to pay for the product in auction. In order to give the intuition, we suppose $h \neq 1, h \neq 2$ and compare 1's bid with 2's bid. Note that from the definition of the dominance, the best alternative portfolio when the buyer does not buy any product from 1 is worse than the one when the buyer does not buy anything from 2. Therefore, only two cases may arise: either $h$ 's product on sale belongs to both portfolios or it belongs only to the best alternative portfolio when the buyer does not buy anything from 1 . In the second case, it is clear that 1 makes a positive bid while 2 makes zero bid. In the first case, we need to think which product is going to replace $h$ 's product in the best alternative portfolio. Since the best alternative portfolio when the buyer does not buy anything from 1 is inferior to the one when the buyer does not buy anything from 2 , the product replacing $h$ 's product is worse in the first portfolio than in the second. This implies that 1 gains more than 2 from purchasing the product of firm $h$. 
Remark 4: Our proposition 8 is similar to the results that O'Brien and Shaffer find (Propositions 4-6) when they study a horizontal merger in a Nash bargaining setup; but they do not make the merger endogenous as we do in Proposition 9.

\section{$9 \quad$ Policy implications and concluding remarks}

In this section, we derive policy implications from our results and discuss issues for future studies.

\subsection{Efficient allocation of slots}

When we consider a static setting and focus on efficient allocation of slots, our results generate the following policy implications. First, bundling such as offering a menu of bundles or "individual prices plus a fixed fee" is socially desirable and should be allowed. Second, regarding pure bundling, in the case of digital goods, the technology-renting strategy is identical to pure bundling and therefore pure bundling of all products belonging to a firm achieves efficient allocation and is socially desirable. This implies that block booking of movies is socially desirable. In contrast, in the case of physical goods, pure bundling can create inefficient equilibria and hence competition authority should be careful. Third, regarding slotting contracts, in the case of digital goods, our analysis implies that prohibiting slotting contracts is socially desirable since then all equilibria are efficient. In contrast, in the case of physical goods, inefficient equilibria can arise either because of charging marginal prices below costs (in the absence of slotting contracts) or because of slotting contracts. Although we have shown that prohibiting firms from charging marginal prices below costs makes all equilibria efficient, in practice it may be difficult to monitor whether firms charge marginal prices below costs (De la Mano-Durand, 2005). Then, prohibiting only slotting contracts may not be enough to achieve efficient allocations.

\subsection{Foreclosure}

Even though we have not formally investigated the issue of foreclosure, our results have some implications on how bundling and slotting contracts affect foreclosure.

Consider first bundling. As we noted in section 2.2, in Whinston (1990)'s revival of the leverage theory, pure bundling serves as a commitment device to be aggressive and therefore can allow to foreclose a rival firm. On the contrary, in our paper, bundling (pure bundling in the case of digital goods) allows a firm to extract more surplus from the buyer by softening competition from rival products. For instance, in the case of digital goods, if an equilibrium 
under individual pricing exists, propositions 7 and 6(i) suggest that all firms' profits are at least weakly higher (and often strictly higher) in any equilibrium under bundling than in the equilibrium under individual pricing. Then bundling (or pure bundling) cannot be an instrument of foreclosure.

This opposite prediction is due to two key differences between Whinston's model and our model. First, Whinston considers a situation in which, the tying product and the tied product do not compete and therefore the firm who sells both products does not suffer from internal competition between his own products. By contrast, in our model, because of the slot constraint, there is competition among all products including competition among products belonging to the same firm. Bundling has an effect of removing internal competition among products belonging to the same firm and therefore each firm can gain from bundling. Second, Whinston assumes that once the incumbent sells the tied product to the buyer, the rival firm cannot induce the buyer to replace it with his own product and at the same time recoup his cost. In our model, this incompatibility assumption fails to hold in the case of digital goods.

Furthermore, we believe that the two different models capture different real world situations. Whinston's model is well adapted to famous cases such as IBM's tying of tabulating machines with tabulating cards or Microsoft's tying of Windows operating system with Internet Explorer. ${ }^{30}$ In these examples, the incumbent is a monopoly in one market and faces competition in the other market and the two products tied together are not substitutes but complements. Our model is well adapted to competition among portfolios such as movies, cigarettes, foods whenever their distributors have limited slots due to limited attention of consumers or limited shelf space. For instance, the leverage theory was originally applied to the movie industry when the Supreme Court prohibited block booking. However, in the case of movies, it is not realistic to assume that movies produced by Paramount Pictures do not compete among themselves while some of them compete with movies produced by other studios. It would be reasonable, as a first approximation, to assume that all movies compete among themselves as we do in our model.

Consider now exclusive dealing (or slotting contracts). Our results suggest that exclusive dealing can be a direct instrument of foreclosure. For instance, consider digital goods. Then, in the absence of slotting contracts, all equilibria are efficient and each firm realizes at least the profit of the technology-renting equilibrium (proposition 6(i)). However, if slotting contracts are allowed, a firm can buy all slots and foreclose rival firms if this is in his interest.

\footnotetext{
${ }^{30}$ Choi and Stefanadis (2001) and Carlton and Waldman (2002) apply Whinston's spirit to Microsoft's tying.
} 


\subsection{Concluding remarks}

As challenging issues for future studies, it would be interesting to explore dynamic implications of the portfolio effects in a setting in which we make the portfolio of each firm endogenous. We can also model the buyer as a downstream firm and study the firm's pricing with respect to final consumers. Even in a relatively simple setting with a monopoly downstream firm, we can study the interaction between bundling at upstream level and bundling at downstream level. But, of course, it would be more interesting to study competition between downstream firms, which is very relevant for cable or digital TV.

\section{References}

[1] Armstrong, Mark (1996). "Multiproduct Nonlinear Pricing." Econometrica, 64, 51-75

[2] Armstrong, Mark (1999). "Price Discrimination by a Many-Product Firm." Review of Economic Studies, 66, 151-168.

[3] Armstrong, Mark and John Vickers (2001). "Competitive Price Discrimination." 32(4): 579-605, RAND Journal of Economics

[4] Armstrong, Mark and John Vickers (2008). "Competitive Nonlinear Pricing and Bundling." forthcoming in Review of Economic Studies

[5] Areeda, P and D. T. Turner (1975). "Predatory Pricing and Related Practices under Section 2 of the Sherman Act." 88: 697-733, Harvard Law Review

[6] Bakos, Yannis and Eric Brynjolfsson (1999). "Bundling Information Goods: Pricing, Profits and Efficiency." Management Science, 45, 1613-1630.

[7] Bernheim, Douglas and Michael Whinston (1985). "Common Marketing Agency as a Device for Facilitating Collusion." RAND Journal of Economics, 15, 269-281.

[8] Bernheim, Douglas and Michael Whinston (1986). "Menu Auctions, Resource Allocation and Economic Influence." Quarterly Journal of Economics, 101, 1-31.

[9] Bernheim, Douglas and Michael Whinston (1998). "Exclusive Dealing." Journal of Political Economy, 106, 64-103.

[10] Bork, Robert H. (1978). The Antitrust Paradox: A Policy at War with Itself. New York, New York: Basic Books. 
[11] Bowman, Ward (1957). "Tying Arrangements and the Leverage Problem," Yale Law Journal, 67, pp.19-36.

[12] Carlton, W. Dennis and Michael Waldman (2002). "The Strategic Use of Tying to Preserve and Create Market Power in Evolving Industries." RAND Journal of Economics, $33(2): 194-220$

[13] Choi, Jay Pil and Stefanadis, Chris (2001). "Tying, Investment, and the Dynamic Leverage Theory", RAND Journal of Economics, pp. 52-71.

[14] De la Mano, Miguel and Benoît Durand (2005). "A Three-Step Structured Rule of Reason to Assess Predation under Article 82." Discussion Paper, Office of the Chief Economist. DG Competition. European Commission.

[15] Edlin, Aaron S., and Daniel L. Rubinfeld (2004). "Exclusion or Efficient Pricing: The 'Big Deal' Bundling of Academic Journals." Antitrust Law Journal, 72, 119-157.

[16] Federal Trade Commission Staff Report (2001). "Report on the Commission Workshop on Slotting Allowances and Other Marketing Practices in the Grocery Industry."

[17] Federal Trade Commission Staff Study (2003). "Slotting Allowances in the Retail Grocery Industry: Selected Case Studies in Five Product Categories."

[18] Hanssen, F. Andrew (2000). "The Block booking of Films Reexamined." Journal of Law and Economics, 43 (2): 395-426

[19] Jeon, Doh-Shin and Domenico Menicucci (2006). "Bundling Electronic Journals and Competition among Publishers." Journal of the European Economic Association, vol.4 (5), September 2006, 1038-83

[20] Jeon, Doh-Shin and Domenico Menicucci (2009). "Bundling and Competition for Slots: Sequential Pricing." Mimeo.

[21] Kenney, Roy W. and Klein, Benjamin (1983). "The Economics of Block Booking." Journal of Law and Economics, 26 (3): 497-540

[22] Kenney, Roy W. and Klein, Benjamin (2000). "How Block booking Facilitated SelfEnforcing Films Contracts." Journal of Law and Economics, 43 (2): 427-35

[23] McAfee, R. Preston, John McMillan, Michael D. Whinston (1989). "Multiproduct Monopoly, Commodity Bundling, and Correlation of Values." Quarterly Journal of Economics, 114, 371-384. 
[24] Nalebuff, Barry (2004). "Bundling as an Entry Barrier." Quarterly Journal of Economics, 119, 159-188.

[25] O'Brien, Daniel and Greg Shaffer (1997). "Non-Linear Supply Contracts, Exclusive Dealing, and Equilibrium Market Foreclosure", Journal of Economics and Management Strategy, 6, 755-785.

[26] O'Brien, Daniel and Greg Shaffer (2005). "Bargaining, bundling, and clout: the portfolio effects of horizontal mergers." RAND Journal of Economics, 36, 573-595

[27] Posner, Richard A. (1976). Antitrust Law: An Economic Perspective, Chicago: University of Chicago Press.

[28] Rochet, Jean-Charles and Lars Stole (2002). "Non-linear Pricing and Random Participation." 69(1): 277-311, Review of Economics Studies.

[29] Salinger, Michael A. (1995). "A Graphical Analysis of Bundling." Journal of Business, $68,85-98$.

[30] Schmalensee, Richard L. (1984). "Gaussian Demand and Commodity Bundling." Journal of Business 57. S211-S230.

[31] Shaffer, Greg (1991). "Capturing Strategic Rent: Full-Line Forcing, Brand Discounts, Aggregate Rebates, and Maximum Resale Price Maintenance." Journal of Industrial Economics 39 (5): 557-575

[32] Stigler, George J. (1968). "A Note on Block Booking." in The Organization of Industry, edited by George J. Stigler. Homewood, Illinois: Richard D. Irwin.

[33] Whinston, Michael D. (1990). "Tying, Foreclosure and Exclusion." American Economic Review, 80, 837-59.

Appendix

Proof of Proposition 1

(i) The proof is organized in three steps

Step 1 In any NE, the buyer buys $k$ products.

Suppose that the buyer buys less than $k$ products, and thus she leaves some slots empty. This implies that less than $k$ products have positive net values. Let $i j$ denote an object in $B^{F B}$ which the buyer does not buy: then certainly its price is larger than $u_{i}^{j}$. Hence, a profitable deviation for firm $i$ exists: set $p_{i j}$ such that $c<p_{i j}<u_{i}^{j}$ (notice that $u_{i}^{j}>c$ since 
$i j \in B^{F B}$ ), so that one more object has positive net value. Then the buyer will still buy the products she was buying previously, in addition to product $i j$, and the profit of firm $i$ will increase by $p_{i j}-c>0$.

Step 2 Let $B$ denote the set of products purchased by the buyer; then $w_{i}^{j}=\bar{w}$ for any $i j \in B$, for some $\bar{w} \geq 0$.

If $i j$ and $i^{\prime} j^{\prime}$ are in $B$ and $w_{i}^{j}>w_{i^{\prime}}^{j^{\prime}}$, then firm $i$ has an incentive to deviate by increasing $p_{i j}$ a bit because the buyer will still buy the objects in $B$, and so firm $i$ will have a higher profit. Hence, $w_{i}^{j}=w_{i^{\prime}}^{j^{\prime}}$ for any $i j$ and $i^{\prime} j^{\prime}$ in $B$ and we denote with $\bar{w}$ this common value. Step 3 In any NE, the slots are occupied by the efficient products, that is $B=B^{F B}$.

Suppose now that the buyer buys $k$ objects but there is some product $i j$ in $B^{F B}$ which she does not buy. Recall that all products in $B$ have the same net value $\bar{w}$ by step 2 , and let $i^{\prime} j^{\prime}$ be the product with the lowest gross value among the products in $B$. Then $i^{\prime} j^{\prime} \notin B^{F B}$ and thus $u_{i^{\prime}}^{j^{\prime}}<u_{i}^{j}$. Furthermore, $p_{i^{\prime} j^{\prime}} \geq c$ must hold, otherwise firm $i^{\prime}$ is better off not selling the product. Let firm $i$ deviate by setting $p_{i j}$ such that $w_{i}^{j}=w_{i^{\prime}}^{j^{\prime}}+\varepsilon$ with $\varepsilon>0$ and smaller than $u_{i}^{j}-u_{i^{\prime}}^{j^{\prime}}$, which means that $p_{i j}=u_{i}^{j}-u_{i^{\prime}}^{j^{\prime}}+p_{i^{\prime} j^{\prime}}-\varepsilon$. Then $i j$ is the product with the highest net value, thus the buyer will buy it and drop $i^{\prime} j^{\prime}$, which has the lowest gross value among the products we was buying previously. This deviation is profitable to firm $i$ : if $i^{\prime} \neq i$, then firm $i$ gains $p_{i j}-c>0$ more $\left(p_{i j}>c\right.$ since $p_{i^{\prime} j^{\prime}} \geq c$ holds and $\left.\varepsilon<u_{i}^{j}-u_{i^{\prime}}^{j^{\prime}}\right)$; if $i^{\prime}=i$, then firm $i$ gains $p_{i j}-p_{i^{\prime} j^{\prime}}=u_{i}^{j}-u_{i^{\prime}}^{j^{\prime}}-\varepsilon>0$ more (again, recall that $\varepsilon<u_{i}^{j}-u_{i^{\prime}}^{j^{\prime}}$ ). Given that $B=B^{F B}$, we use $w^{F B}$ instead of $\bar{w}$.

(ii) The value of $w^{F B}$ is equal to $\max \left\{0, \max _{i j \in \mathcal{B} \backslash B^{F B}}\left\{w_{i}^{j}\right\}\right\}$ because if $w^{F B}$ is smaller than $\max \left\{0, \max _{i j \in \mathcal{B} \backslash B^{F B}}\left\{w_{i}^{j}\right\}\right\}$, then the buyer does not buy all the products in $B^{F B}$; if $w^{F B}>\max \left\{0, \max _{i j \in \mathcal{B} \backslash B^{F B}}\left\{w_{i}^{j}\right\}\right\}$, then each firm $i \leq n^{F B}$ can deviate by slightly increasing the prices of his products in $B_{i}^{F B}$, and the buyer will still purchase them. Now we prove that $w^{F B} \geq u^{k+1}-c$. If $w^{F B}<u^{k+1}-c$, consider the firm $i^{*}$ which offers the product $i^{*} j^{*}$ with value $u^{k+1}$, and let this firm set $p_{i^{*} j^{*}}=c+\varepsilon$ with $\varepsilon>0$ and small, so that $w_{i^{*}}^{j^{*}}=u^{k+1}-c-\varepsilon>w^{F B}$ : product $i^{*} j^{*}$ has the highest net value and the buyer purchases it. If $B_{i^{*}}^{F B}=\emptyset$, this is a profitable deviation for firm $i^{*}$. If instead $B_{i^{*}}^{F B} \neq \emptyset$, then let this firm reduce by $\frac{\varepsilon}{k}$ the price of each of his $q_{i}^{F B}$ products in $B_{i^{*}}^{F B}$. This guarantees that the buyer purchases (at least) $B_{i}^{F B} \cup\left\{i^{*} j^{*}\right\}$ and therefore the profit of firm $i$ increases by $\varepsilon-q_{i}^{F B} \frac{\varepsilon}{k}>0$.

Since $w^{F B} \geq u^{k+1}-c, p_{i j} \leq u_{i}^{j}-\left(u^{k+1}-c\right)$ holds for any $i j \in B^{F B}$ and the profit of firm $i$ is weakly smaller than $U_{i}^{F B}-u^{k+1} q_{i}^{F B}$.

(iii) From (ii) we know $w^{F B} \geq u^{k+1}-c$. $u^{k+1}-u^{k+2}>c$ implies that there is no product $i j \in \mathcal{B} \backslash B^{F B}$ different from $i^{*} j^{*}$ such that $w_{i}^{j}=w^{F B}$. Indeed, if such $i j \in \mathcal{B} \backslash B^{F B}$ exists, we would get $w^{F B}=w_{i}^{j}=u_{i}^{j}-p_{i j} \leq u_{i}^{j}<u_{i^{*}}^{j^{*}}-c$ (the first inequality comes from $p_{i j} \geq 0$; the 
second one comes from $u^{k+1}-u^{k+2}>c$ ), and this violates $w^{F B} \geq u_{i^{*}}^{j^{*}}-c$. Therefore, we must have $u_{i^{*}}^{j^{*}}-p_{i^{*} j^{*}}=w^{F B}$, and thus $p_{i^{*} j^{*}} \leq c$, and $w^{F B}>u_{i^{\prime}}^{j^{\prime}}-p_{i^{\prime} j^{\prime}}$ for any $i^{\prime} j^{\prime} \in \mathcal{B} \backslash B^{F B}$, $i^{\prime} j^{\prime} \neq i^{*} j^{*}$. Then, let firm $i^{*}$ deviate by increasing both the price of object $i^{*} j^{*}$ and $p_{i^{*} j}$ for any $i^{*} j \in B_{i^{*}}^{F B} \neq \emptyset$ (i.e., the prices of all his products in $B_{i^{*}}^{F B}$ ) by the same $\varepsilon>0$ such that $u^{k+1}-p_{i^{*} j^{*}}-\varepsilon$ is larger than $u_{i^{\prime}}^{j^{\prime}}-p_{i^{\prime} j^{\prime}}$ for any $i^{\prime} j^{\prime} \in \mathcal{B} \backslash B^{F B}, i^{\prime} j^{\prime} \neq i^{*} j^{*}$. Then the buyer still buys all products in $B^{F B}$, and $i^{*}$ s profit is increased.

\section{Proof of Lemma 1}

Consider any arbitrary profile of strategies $\left(s_{i}, s_{-i}\right)$ and let $\pi_{i}$ be the profit of firm $i$ given $\left(s_{i}, s_{-i}\right)$. We show that $i$ can achieve the same profit $\pi_{i}$ by playing $\operatorname{tr}_{i} \in T R_{i}$ such that $F_{i}=\pi_{i}$. This fact is obvious if $\pi_{i}=0$ and therefore we consider the case of $\pi_{i}>0$. In order to prove this result, it suffices to show that the buyer buys at least one product from $i$ when $i$ plays $t r_{i}$. We find that, (i) given $\left(t r_{i}, s_{-i}\right)$, the buyer can make the same payoff that she makes with $\left(s_{i}, s_{-i}\right)$ since she can buy the same products, with the same outlay; (ii) given $\left(t r_{i}, s_{-i}\right)$, the buyer cannot realize a higher payoff than with $\left(s_{i}, s_{-i}\right)$ without buying at least one product of firm $i$, because otherwise she would not buy anything from $i$ given $\left(s_{i}, s_{-i}\right)$, and this contradicts $\pi_{i}>0$.

\section{Proof of Proposition 3}

We split the proof into two steps.

Step 1 When the sellers play $\left(t r_{1}^{*}, \ldots, t r_{n}^{*}\right)$, the buyer buys the products in $B^{F B}$ and thus each firm $i$ 's profit is $F_{i}^{*}$ while the buyer's payoff is $\sum_{i=1}^{n^{F B}}\left(U_{-i}^{S B}-c q_{-i}^{S B}\right)$.

We start by proving by contradiction that the buyer buys at least some products from (say) firm 1 ; the same argument applies for firm $i=2, \ldots, n^{F B}$. Suppose that the buyer buys nothing from firm 1 , but she buys $\bar{q}$ products from firms -1 , with values $\tilde{u}_{-1}^{1}, \ldots, \tilde{u}_{-1}^{\bar{q}}$ such that $\tilde{u}_{-1}^{1} \geq \ldots \geq \tilde{u}_{-1}^{\bar{q}}$. Obviously, $\bar{q} \leq k$ since buying more than $k$ products implies that some of them would not be used: then the buyer may reduce her outlay without reducing her gross payoff. Actually, however, $\bar{q} \leq k-q_{1}^{F B}+q_{-1}^{S B}$ must hold since $p_{i j}=c$ for any $i=2, \ldots, n$ and any $j=1, \ldots, k$ and there are only $k-q_{1}^{F B}+q_{-1}^{S B}$ products in the portfolios of firms -1 with values not lower than $c$. But then we can prove that for any $\bar{q} \leq k-q_{1}^{F B}+q_{-1}^{S B}$, the buyer can increase her payoff by buying from 1 the products in $B_{1}^{F B}$. First, consider the case in which $\bar{q} \leq k-q_{1}^{F B}$. Then, it is obvious that the buyer can increase her payoff by simply buying the products in $B_{1}^{F B}$ in addition to buying from firms -1 the products of values $\tilde{u}_{-1}^{1}, \ldots, \tilde{u}_{-1}^{\bar{q}}$. Second, consider the case in which $k-q_{1}^{F B}<\bar{q} \leq k-q_{1}^{F B}+q_{-1}^{S B}$. Then, we show below that the buyer can increase her payoff by buying the products in $B_{1}^{F B}$ 
and not buying from firms -1 the products with values $\tilde{u}_{-1}^{k-q_{1}^{F B}+1}, \ldots, \tilde{u}_{-1}^{\bar{q}}$. This changes the buyer's payoff by ${ }^{31}$

$$
\begin{aligned}
\Delta \pi_{0} & \geq-F_{1}^{*}-c q_{1}^{F B}+U_{1}^{F B}-\sum_{j=1}^{\bar{q}-k+q_{1}^{F B}}\left(\tilde{u}_{-1}^{k-q_{1}^{F B}+j}-c\right) \\
& =u_{-1}^{k-q_{1}^{F B}+1}+\ldots+u_{-1}^{k-q_{1}^{F B}+q_{-1}^{S B}}-c q_{-1}^{S B}-\left[\tilde{u}_{-1}^{k-q_{1}^{F B}+1}+\ldots+\tilde{u}_{-1}^{\bar{q}}-c\left(\bar{q}-k+q_{1}^{F B}\right)\right] \\
& \geq u_{-1}^{k-q_{1}^{F B}+1}+\ldots+u_{-1}^{k-q_{1}^{F B}+q_{-1}^{S B}}-c q_{-1}^{S B}-\left[u_{-1}^{k-q_{1}^{F B}+1}+\ldots+u_{-1}^{\bar{q}}-c\left(\bar{q}-k+q_{1}^{F B}\right)\right]
\end{aligned}
$$

We note that the set $\left\{u_{-1}^{k-q_{1}^{F B}+1}, \ldots, u_{-1}^{\bar{q}}\right\}$ is a subset of $\left\{u_{-1}^{k-q_{1}^{F B}+1}, \ldots, u_{-1}^{k-q_{1}^{F B}+q_{-1}^{S B}}\right\}$, and the set $\left\{u_{-1}^{k-q_{1}^{F B}+1}, \ldots, u_{-1}^{k-q_{1}^{F B}+q_{-1}^{S B}}\right\} \backslash\left\{u_{-1}^{k-q_{1}^{F B}+1}, \ldots, u_{-1}^{\bar{q}}\right\}$ has cardinality $q_{-1}^{S B}-\left(\bar{q}-k+q_{1}^{F B}\right) \geq 0$. As $u_{-1}^{k-q_{1}^{F B}+q_{-1}^{S B}} \geq c, \Delta \pi_{0}$ is non-negative.

In this way we have proved that the buyer buys at least one product of firm 1 , and then pays the fixed fee $F_{1}^{*}$. The same argument holds for any other firm $i=2, \ldots, n^{F B}$, and this reveals that the buyer buys at least all the products in $B_{i}^{F B}, i=1, \ldots, n^{F B}$. But since she will not buy more than $k$ products, it must be the case that she buys $B_{1}^{F B} \cup \ldots \cup B_{n^{F B}}^{F B}$ and buys nothing from firm $i=n^{F B}+1, \ldots, n$.

Step 2 When each firm $h \neq i$ plays $t r_{h}^{*}$, firm $i$ cannot make a profit larger than $F_{i}^{*}$. We prove this claim for firm 1 , and the same argument applies for $i=2, \ldots, n$. From Lemma 1 , it is enough to consider firm 1's deviation in the set of technology-renting strategies $T R_{1}$. Obviously, firm 1 has no incentive to decrease $F_{1}$ below $F_{1}^{*}$. We now prove that firm 1 has no incentive to increase $F_{1}$ above $F_{1}^{*}$. Note first that from the fact that $F_{1}^{*}$ makes the buyer indifferent between renting 1's technology or not, the buyer can achieve the payoff equal to $\pi_{0}^{*}$ without buying any product from firm 1 . Suppose now that 1 chooses $F_{1}=F_{1}^{*}+\varepsilon$ for $\varepsilon>0$. We need to prove that the buyer will not buy any product from 1 . The buyer can make a profit of $\pi_{0}^{*}$ by buying only from firms -1 , and she cannot make a profit $\pi \geq \pi_{0}^{*}$ by buying one or more products from 1 (given $F_{1}=F_{1}^{*}+\varepsilon$ ), because if she could then she would make at least profit $\pi+\varepsilon>\pi_{0}^{*}$ before the deviation of 1: a contradiction.

\section{Proof of Proposition 4}

Consider a profile of strategies $\left(s_{1}, \ldots, s_{n}\right)$ such that the buyer buys a portfolio of products $B=B_{1} \cup \ldots \cup B_{n}$ and, for instance, $B_{1}$ does not include all the products in $B_{1}^{F B}$; that is, $B_{1}^{F B} \backslash B_{1} \neq \emptyset$. Let $\pi_{1}$ denote the profit of firm 1 and let $\pi_{0}$ denote the buyer's payoff given these strategies. We prove that there exists a profitable deviation for firm 1 , and thus

\footnotetext{
${ }^{31}$ The first inequality holds because, when not buying from firms -1 the products with values $\tilde{u}_{-1}^{k-q_{1}^{F B}+1}, \ldots, \tilde{u}_{-1}^{\bar{q}}$, it is conceivable that the buyer stops renting the technology of some firms.
} 
$\left(s_{1}, \ldots, s_{n}\right)$ is not a NE. Consider now the strategy $t r_{1} \in T R_{1}$ of firm 1 with $F_{1}=\pi_{1}+\varepsilon$ for $\varepsilon>0$ and small. We below prove that the buyer buys at least one product from firm 1 , and therefore 1's profit increases to $\pi_{1}+\varepsilon$. In order to prove this, we first note that if the buyer does not buy any product from 1 , she cannot make a payoff higher than $\pi_{0}$ [otherwise she would not buy $B$ given $\left.\left(s_{1}, \ldots, s_{n}\right)\right]$. Then it suffices to show that the buyer can earn more than $\pi_{0}$ by purchasing $B \cup\{1 j\}$, with $1 j \in B_{1}^{F B} \backslash B_{1}$, which includes at least one product offered by firm 1 . Consider first the case in which $\#(B)<k$. Then, the buyer's payoff from buying $B \cup\{1 j\}$ is equal to $\pi_{0}+u_{1}^{j}-c-\varepsilon$, which is larger than $\pi_{0}$ since $1 j \in B^{F B}$ implies $u_{1}^{j}>c$. Consider now the case in which $\#(B)=k$. In this case, the buyer's payoff from $B \cup\{1 j\}$ is $\pi_{0}+u_{1}^{j}-\varepsilon-c-u_{h}^{j^{\prime}}$, where $h j^{\prime}$ denotes the lowest valued product in $B$, which the buyer removes from one slot to make room for product $1 j$. We know that $u_{1}^{j} \geq u^{k}$ since $1 j \in B^{F B}$ and $-u_{h}^{j^{\prime}} \geq-u^{k+1}$ since $h j^{\prime} \notin B^{F B}$, hence $u_{1}^{j}-\varepsilon-c-u_{h}^{j^{\prime}} \geq u^{k}-u^{k+1}-\varepsilon-c>0$ holds given that $u^{k}-u^{k+1}>c$.

\section{Proof of Proposition 5}

The proof is similar to the proof of Proposition 4. Consider a profile of strategies $\left(s_{1}, \ldots, s_{n}\right)$ such that the buyer buys $B=B_{1} \cup \ldots \cup B_{n}$ and, for instance, $B_{1}$ does not include all the products in $B_{1}^{F B}$; there exists a product $1 j \in B_{1}^{F B} \backslash B_{1}$. Let $\pi_{1}$ denote the profit of firm 1 given these strategies, while $\pi_{0}$ represents the buyer's payoff. We prove that there exists a profitable deviation for firm 1 , and thus $\left(s_{1}, \ldots, s_{n}\right)$ is not a NE. Consider the strategy of firm 1 in $T R_{1}$ such that $F_{1}=\pi_{1}+\varepsilon$ (for $\varepsilon>0$ and small). In order to prove that this is a profitable deviation for 1 , it suffices to show that the buyer buys at least one product from firm 1, as this yields 1 a profit of $\pi_{1}+\varepsilon$ which is larger than $\pi_{1}$. Note first that in the case in which the buyer does not buy any product from 1 , she can make at most a profit equal to $\pi_{0}$. Consider first the case in which $\#(B)<k$. Then, the buyer can buy $B \cup\{1 j\}$ and gets a payoff equal to $\pi_{0}+u_{1}^{j}-c-\varepsilon$, which is larger than $\pi_{0}$ since $1 j \in B^{F B}$ implies $u_{1}^{j}>c$. Consider now the case of $\#(B)=k$. Then the buyer can buy $B \cup\{1 j\} /\left\{h j^{\prime}\right\}$ where $h j^{\prime}$ denotes the lowest valued product in $B$ : the buyer replaces $h j^{\prime}$ with $1 j$. Then, the change in the buyer's payoff is $u_{1}^{j}-c-\varepsilon-u_{h}^{j^{\prime}}+\left[P_{h}\left(B_{h}\right)-P_{h}\left(B_{h} \backslash\left\{h j^{\prime}\right\}\right)\right]$, which is at least as large as $u_{1}^{j}-\varepsilon-u_{h}^{j^{\prime}}>0$ since $P_{h}\left(B_{h}\right)-P_{h}\left(B_{h} \backslash\left\{h j^{\prime}\right\}\right) \geq c$ by (2). Thus, after 1's deviation, the buyer will buy at least one product of 1 .

\section{Proof of Proposition 6}

(i) If suffices to prove that if firm $i$ plays $t r_{i}^{*}$, then the buyer buys at least one product of firm $i$ whatever are the strategies played by the other firms; this implies $\pi_{i}=F_{i}^{*}$, and 
thus $F_{i}^{*}$ is a lower bound for the profit that seller $i$ can realize. Indeed, even in the case in which the buyer has already bought all the products in $\mathcal{B}_{-i}$, she is willing to pay $F_{i}^{*}$ to substitute the products in $B_{-i}^{S B}$ with the products in $B_{i}^{F B}$, given that $F_{i}^{*}=U_{i}^{F B}-U_{-i}^{S B}$.

(ii) The proof is by contradiction. Suppose there exists a NE such that 1 makes a profit higher than $F_{1}^{*}=U_{1}^{F B}-c q_{1}^{F B}-\left(U_{-1}^{S B}-c q_{-1}^{S B}\right)$. Precisely, suppose that 1 sells a bundle $B_{1} \subset \mathcal{B}_{1}$ such that $q_{1}=\# B_{1}$, and 2 sells a bundle $B_{2} \subset \mathcal{B}_{2}$ such that $q_{2}=\# B_{2}$. Then 1 's revenue $P_{1}\left(B_{1}\right)$ is larger than $F_{1}^{*}+c q_{1}$, while 2 's revenue is $\bar{P}_{2} \equiv P_{2}\left(B_{2}\right)$. The payoff of the buyer is

$$
\alpha \equiv \sum_{1 j \in B_{1}} u_{1}^{j}+\sum_{2 j \in B_{2}} u_{2}^{j}-P_{1}\left(B_{1}\right)-\bar{P}_{2}
$$

and it is clear that this is smaller than

$$
\beta \equiv \sum_{1 j \in B_{1}} u_{1}^{j}+\sum_{2 j \in B_{2}} u_{2}^{j}-\left(F_{1}^{*}+c q_{1}\right)-\bar{P}_{2}
$$

since $P_{1}\left(B_{1}\right)>F_{1}^{*}+c q_{1}$. We prove that the latter inequality implies the existence of a profitable deviation for firm 2 .

Let 2 deviate by using a technology renting strategy with $F_{2}=\bar{P}_{2}-c q_{2}+\varepsilon$, with $\varepsilon>0$ and small. Since in the candidate NE considered in the beginning the profit of 2 is equal to $\bar{P}_{2}-c q_{2}$, this deviation of 2 is profitable if and only if the buyer buys at least one object from 2. In order to prove that this is the case, we notice that if the buyer does not buy anything from firm 2, then she buys only bundles offered by 1 , and they cannot yield the buyer a payoff larger than $\alpha$, otherwise we obtain a contradiction with the fact that the initial candidate is a NE. Let $\tilde{B}_{2}=B_{2}^{F B} \cup B_{-1}^{S B}$ denote the bundle of 2 which includes his best $k_{2}=q_{2}^{F B}+q_{-1}^{S B}$ products. We show below that the buyer's profit if she buys only $\tilde{B}_{2}$ is larger than $\alpha$, and thus we infer that she will definitely buy at least one product from firm 2.

Suppose for the moment that $\varepsilon=0$. Then the payoff of the buyer from buying only $\tilde{B}_{2}$ is

$$
\gamma \equiv U_{2}^{F B} \cup U_{-1}^{S B}-\bar{P}_{2}-c\left(k_{2}-q_{2}\right)
$$

and we below prove $\gamma \geq \beta$; then, since $\beta>\alpha$, we obtain $\gamma>\alpha$ for the case in which $\varepsilon=0$, which implies that $\gamma>\alpha$ holds for $\varepsilon(>0)$ small. The inequality $\gamma \geq \beta$ is equivalent to

$$
U_{2}^{F B} \cup U_{-1}^{S B}-c\left(k_{2}-q_{2}\right) \geq \sum_{1 j \in B_{1}} u_{1}^{j}+\sum_{2 j \in B_{2}} u_{2}^{j}-F_{1}^{*}-c q_{1}
$$

and, recalling that $F_{1}^{*}=U_{1}^{F B}-c q_{1}^{F B}-\left(U_{-1}^{S B}-c q_{-1}^{S B}\right)$, we can write the equivalent condition:

$$
\begin{aligned}
U_{2}^{F B} \cup U_{-1}^{S B}-c\left(q_{2}^{F B}+q_{-1}^{S B}-q_{2}\right) & \geq \sum_{1 j \in B_{1}} u_{1}^{j}+\sum_{2 j \in B_{2}} u_{2}^{j}-\left[U_{1}^{F B}-c q_{1}^{F B}-\left(U_{-1}^{S B}-c q_{-1}^{S B}\right)\right]-c q_{1} \\
\text { or } \quad U_{1}^{F B}-c q_{1}^{F B}+U_{2}^{F B}-c q_{2}^{F B} \geq & \geq \sum_{1 j \in B_{1}} u_{1}^{j}-c q_{1}+\sum_{2 j \in B_{2}} u_{2}^{j}-c q_{2}
\end{aligned}
$$


and this inequality is obviously satisfied by definition of $q_{1}^{F B}, q_{2}^{F B}, U_{1}^{F B}, U_{2}^{F B}$.

(iii) Here we prove that when firms are required to satisfy (2), in any NE the profit of firm $i$ is at least $F_{i}^{*}$. This result holds for any $n \geq 2$, but in the case of $n=2$ [jointly with (ii)] it implies the statement in Proposition 6(iii). ${ }^{32}$

This claim is obvious for $i=n^{F B}+1, \ldots, n$, as $F_{i}^{*}=0$ for these firms. About firm $i=$ $1, \ldots, n^{F B}$, we show that if firm $i$ plays (1), then (regardless of the strategies followed by the other firms), the buyer buys $B_{i}^{F B}$; hence, firm $i$ can get a profit equal to $F_{i}^{*}$; this establishes that his equilibrium profit is not lower than $F_{i}^{*}$. The proof is by contradiction, is written for firm 1, and follows closely the proof of Step 1 in the proof of Proposition 3. Suppose that 1 plays $t r_{1}^{*}$ and the buyer buys nothing from firm 1 , while she buys $\bar{q}$ products from firms -1 , with values $\tilde{u}_{-1}^{1}, \ldots, \tilde{u}_{-1}^{\bar{q}}$ such that $\tilde{u}_{-1}^{1} \geq \ldots \geq \tilde{u}_{-1}^{\bar{q}}$. Obviously, $\bar{q} \leq k-q_{1}^{F B}+q_{-1}^{S B}$ because of (2) and because the best alternative portfolio without buying any product from 1 cannot include more than $k-q_{1}^{F B}+q_{-1}^{S B}$ products from the definition of $q_{1}^{F B}$ and $q_{-1}^{S B}$. But then the buyer can increase her payoff by buying from 1 the products in $B_{1}^{F B}$. To prove this, consider first the case of $\bar{q} \leq k-q_{1}^{F B}$. Then, it is obvious that the buyer can increase her payoff by simply buying the products in $B_{1}^{F B}$ in addition to buying from firms -1 the products with values $\tilde{u}_{-1}^{1}, \ldots, \tilde{u}_{-1}^{\bar{q}}$. Second, consider the case in which $k-q_{1}^{F B}<\bar{q} \leq k-q_{1}^{F B}+q_{-1}^{S B}$. Then, we show below that the buyer can increase her payoff by buying the products in $B_{1}^{F B}$ and not buying from firms -1 products of values $\tilde{u}_{-1}^{k-q_{1}^{F B}+1}, \ldots, \tilde{u}_{-1}^{\bar{q}}$. This changes the buyer's payoff by

$$
\Delta \pi_{0}=-F_{1}^{*}-c q_{1}^{F B}+U_{1}^{F B}-\sum_{t=1}^{\bar{q}-k+q_{1}^{F B}} \tilde{u}_{-1}^{k-q_{1}^{F B}+t}+E
$$

where $E$ is the money that the buyer saves by not buying the products with values $\tilde{u}_{-1}^{k-q_{1}^{F B}+1}, \ldots, \tilde{u}_{-1}^{\bar{q}}$. Because of $(2), E$ is not smaller than $c\left(\bar{q}-k+q_{1}^{F B}\right)$ and therefore we have:

$$
\Delta \pi_{0} \geq-F_{1}^{*}-c q_{1}^{F B}+U_{1}^{F B}-\sum_{t=1}^{\bar{q}-k+q_{1}^{F B}}\left(\tilde{u}_{-1}^{k-q_{1}^{F B}+t}-c\right)
$$

Then we can argue like in the proof of Step 1 in the proof of Proposition 1 to prove that the latter term is non-negative.

\section{Proof of Proposition 8}

\footnotetext{
${ }^{32}$ In particular, the proof of Proposition 6(ii) applies verbatim also to the setting in which firms must satisfy (2), since the deviation which is proposed for firm 2 uses a technology renting strategy.
} 
We take care of only part (ii) when $q_{i}^{F B} \geq 1$ and $q_{h}^{F B} \geq 1$ since the proof of part (i) is given just after the statement.

Before the merger, the profits of firms $i$ and $h$ are $U_{i}^{F B}-c q_{i}^{F B}-\left(U_{-i}^{S B}-c q_{-i}^{S B}\right)$ and $U_{h}^{F B}-$ $c q_{h}^{F B}-\left(U_{-h}^{S B}-c q_{-h}^{S B}\right)$, respectively. After the merger, the profit of $i+h$ is $U_{i+h}^{F B}-c q_{i+h}^{F B}-$ $\left(U_{-(i+h)}^{S B}-c q_{-(i+h)}^{S B}\right)$. Since $q_{i+h}^{F B}=q_{i}^{F B}+q_{h}^{F B}$ and $U_{i+h}^{F B}=U_{i}^{F B}+U_{h}^{F B}$, the inequality

$U_{i+h}^{F B}-c q_{i+h}^{F B}-\left(U_{-(i+h)}^{S B}-c q_{-(i+h)}^{S B}\right) \geq U_{i}^{F B}-c q_{i}^{F B}-\left(U_{-i}^{S B}-c q_{-i}^{S B}\right)+U_{h}^{F B}-c q_{h}^{F B}-\left(U_{-h}^{S B}-c q_{-h}^{S B}\right)$

is equivalent to

$$
U_{-i}^{S B}-c q_{-i}^{S B}+U_{-h}^{S B}-c q_{-h}^{S B} \geq U_{-(i+h)}^{S B}-c q_{-(i+h)}^{S B} .
$$

We prove that (3) holds with equality if $\max \left\{u_{-i}^{k-q_{i}^{F B}+1}-c, 0\right\}=\max \left\{u_{-h}^{k-q_{h}^{F B}+1}-c, 0\right\}=$ $\max \left\{u_{-(i+h)}^{k}-c, 0\right\}$ and with strict inequality otherwise.

Step 1 When $q_{-i}^{S B}<q_{i}^{F B}$ and/or $q_{-h}^{S B}<q_{h}^{F B}$, (3) holds with equality if $\max \left\{u_{-i}^{k-q_{i}^{F B}+1}-\right.$ $c, 0\}=\max \left\{u_{-h}^{k-q_{h}^{F B}+1}-c, 0\right\}=0$, otherwise it holds with strict inequality.

Proof. From the definition of $q_{-i}^{S B}$, it is clear that if $q_{-i}^{S B}<q_{i}^{F B}$ (respectively, $q_{-h}^{S B}<q_{h}^{F B}$ ), then $q_{-(i+h)}^{S B} \leq q_{-i}^{S B}$ (respectively, $q_{-(i+h)}^{S B} \leq q_{-h}^{S B}$ ) and $U_{-i}^{S B}-c q_{-i}^{S B} \geq U_{-(i+h)}^{S B}-c q_{-(i+h)}^{S B}$ (respectively, $U_{-h}^{S B}-c q_{-h}^{S B} \geq U_{-(i+h)}^{S B}-c q_{-(i+h)}^{S B}$ ). Hence, (3) holds with strict inequality unless $U_{-i}^{S B}-c q_{-i}^{S B}=U_{-h}^{S B}-c q_{-h}^{S B}=0$, and the latter condition is satisfied if and only if $u_{-i}^{k-q_{i}^{F B}+1} \leq c$ and $u_{-h}^{k-q_{h}^{F B}+1} \leq c$.

Step 2 When $q_{-i}^{S B}=q_{i}^{F B}$ and $q_{-h}^{S B}=q_{h}^{F B}$, (3) holds with strict inequality unless $\max \left\{u_{-i}^{k-q_{i}^{F B}+1}-\right.$ $c, 0\}=\max \left\{u_{-h}^{k-q_{h}^{F B}+1}-c, 0\right\}=\max \left\{u_{-(i+h)}^{k}-c, 0\right\}$.

Proof. Given that $q_{-i}^{S B}=q_{i}^{F B}$ and $q_{-h}^{S B}=q_{h}^{F B},(3)$ reduces to

$$
\begin{gathered}
\left(u_{-i}^{k-q_{i}^{F B}+1}-c\right)+\ldots+\left(u_{-i}^{k}-c\right)+\left(u_{-h}^{k-q_{h}^{F B}+1}-c\right)+\ldots+\left(u_{-h}^{k}-c\right) \\
\geq \max \left\{u_{-(i+h)}^{k-q_{i}^{F B}-q_{h}^{F B}+1}-c, 0\right\}+\ldots+\max \left\{u_{-(i+h)}^{k}-c, 0\right\}
\end{gathered}
$$

Since $u_{-i}^{k-q_{i}^{F B}+j} \geq u_{-(i+h)}^{k-q_{i}^{F B}-q_{h}^{F B}+j}$ for $j=1, \ldots, q_{i}^{F B}$ and $u_{-h}^{k-q_{h}^{F B}+j} \geq u_{-(i+h)}^{k-q_{h}^{F B}-q_{i}^{F B}+j} \geq u_{-(i+h)}^{k-q_{h}^{F B}+j}$ for $j=1, \ldots, q_{h}^{F B}$, we infer that the equality holds in (4) if and only if $u_{-i}^{k-q_{i}^{F B}+j}-c=$ $\max \left\{u_{-(i+h)}^{k-q_{i}^{F B}-q_{h}^{F B}+j}-c, 0\right\}$ for $j=1, \ldots, q_{i}^{F B}$ and $u_{-h}^{k-q_{h}^{F B}+j}-c=\max \left\{u_{-(i+h)}^{k-q_{h}^{F B}-q_{i}^{F B}+j}-\right.$ $c, 0\}=\max \left\{u_{-(i+h)}^{k-q_{h}^{F B}+j}-c, 0\right\}$ for $j=1, \ldots, q_{h}^{F B}$. This occurs if and only if $u_{-i}^{k-q_{i}^{F B}+1}-c=$ $u_{-h}^{k-q_{h}^{F B}+1}-c=\max \left\{u_{-(i+h)}^{k}-c, 0\right\}$, and this condition is equivalent to $\max \left\{u_{-i}^{k-q_{i}^{F B}+1}\right.$ $c, 0\}=\max \left\{u_{-h}^{k-q_{h}^{F B}+1}-c, 0\right\}=\max \left\{u_{-(i+h)}^{k}-c, 0\right\}$ since $q_{-i}^{S B} \geq 1$ and $q_{-h}^{S B} \geq 1$ imply $u_{-i}^{k-q_{i}^{F B}+1}-c=\max \left\{u_{-i}^{k-q_{i}^{F B}+1}-c, 0\right\}$ and $u_{-h}^{k-q_{h}^{F B}+1}-c=\max \left\{u_{-h}^{k-q_{h}^{F B}+1}-c, 0\right\}$.

\section{Proof of Proposition 9}


We only need to prove (ii), and for this purpose we show (without loss of generality) that $u_{-2}^{k+1} \geq u_{-1}^{k+1}$. Recall that $u_{-2}^{k+1}$ is the value of the $(k+1)$-th best product in $B_{-2}$, and consider the set $\tilde{B}_{-2} \equiv B_{-2} \backslash B_{-2}^{F B}$. Since $B_{-2}^{F B}$ is composed of $k-q_{2}^{F B}$ objects, $u_{-2}^{k+1}$ is the value of the $\left(q_{2}^{F B}+1\right)$-th best product in $\tilde{B}_{-2}$. By definition, $\tilde{B}_{-2}$ includes all non-first-best products of firms -2 , and thus products with values $u_{1}^{q_{1}^{F^{B}}+1}, \ldots, u_{1}^{k}$ and the non-first-best products of firms $3, \ldots, n$ - let $\tilde{B}_{-(1+2)} \equiv \tilde{B}_{-2} \backslash B_{1}$ denote the set of the latter products.

Likewise, $u_{-1}^{k+1}$ is the value of the $\left(q_{1}^{F B}+1\right)$-th best product in $\tilde{B}_{-1} \equiv B_{-1} \backslash B_{-1}^{F B}$, which is composed of products with values $u_{2}^{q_{2}^{F B}+1}, \ldots, u_{2}^{q_{1}^{F B}}, u_{2}^{q_{1}^{F B}+1}, \ldots, u_{2}^{k}$ and by the products in $\tilde{B}_{-(1+2)}$. In order to prove that $u_{-2}^{k+1} \geq u_{-1}^{k+1}$, let us consider the values of $u_{2}^{q_{2}^{F B}+1}, \ldots, u_{2}^{q_{1}^{F B}}, u_{2}^{q_{1}^{F B}+1}, \ldots, u_{2}^{k}$ that maximize the value of $u_{-1}^{k+1}$ under the assumption that the portfolio of firm 1 dominates the portfolio of firm 2 . Then the values $u_{2}^{q_{2}^{F B}+1}, \ldots, u_{2}^{q_{1}^{F B}}$ should be the largest possible, and the following equalities should hold: $u_{1}^{q_{1}^{F B}+1}=u_{2}^{q_{1}^{F B}+1}, \ldots, u_{1}^{k}=u_{2}^{k}$. But in this case, we obtain $u_{-2}^{k+1}=u_{-1}^{k+1}$, as (i) $u_{-2}^{k+1}$ is the value of the $\left(q_{2}^{F B}+1\right)$-th best product in $\tilde{B}_{-2}$, and $u_{-1}^{k+1}$ is the value of the $\left(q_{1}^{F B}+1\right)$-th best product in $\tilde{B}_{-1}$; (ii) $\tilde{B}_{-1}$ includes the same products as $\tilde{B}_{-2}$, in addition to the $q_{1}^{F B}-q_{2}^{F B}$ number of products with the values $u_{2}^{q_{2}^{F B}+1}, \ldots, u_{2}^{q_{1}^{F B}}$ (iii) $q_{1}^{F B}-q_{2}^{F B}$ is just the difference between $q_{1}^{F B}+1$ and $q_{2}^{F B}+1 .^{33}$

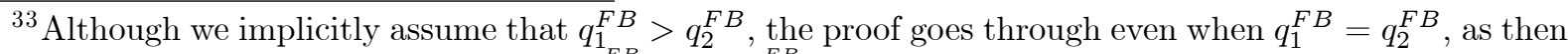
we need to consider the case in which $u_{1}^{q_{1}^{F B}+1}=u_{2}^{q_{1}^{F B}+1}, \ldots, u_{1}^{k}=u_{2}^{k}$. In this case $\tilde{B}_{-1}$ and $\tilde{B}_{-2}$ include products with exactly the same values, and thus $q_{1}^{F B}=q_{2}^{F B}$ implies $u_{-2}^{k+1}=u_{-1}^{k+1}$.
} 